Available online at http://www.mecs-press.net/ijmsc

\title{
Solving Bi-matrix Games in Tourism Planning Management under Rough Interval Approach
}

\author{
M. G. Brikaa ${ }^{\mathrm{a}, \mathrm{b},{ }^{*}, \text { El-Saeed Ammar }}{ }^{\mathrm{c}}$, Zhoushun Zheng ${ }^{\mathrm{a}}$ \\ ${ }^{a}$ School of Mathematics and Statistics, Central South University, Changsha 410083, Hunan, PR China \\ ${ }^{b}$ Department of Basic Science Faculty of Computers \& Informatics. Suez Canal University 41522, Ismailia, \\ Egypt \\ ${ }^{c}$ Department of Mathematics Faculty of Science. Tanta University, Tanta, Egypt
}

Received: 29 May 2019; Accepted: 13 July 2019; Published: 08 November 2019

\begin{abstract}
The aim of this article is to propose a novel and simple technique for solving bi-matrix games with rough intervals payoffs. Since the payoffs of the rough bi-matrix games are rough intervals, then its value is also a rough interval. In this technique, we derived four bilinear programming problems, which are used to obtain the upper lower bound, lower lower bound, lower upper bound and upper upper bound of the rough interval values of the players in rough bi-matrix games which we called in this article as 'solution space'. Moreover, the expected value operator and trust measure of rough interval have been used to find the $\alpha$-trust equilibrium strategies and the expected equilibrium strategies of rough interval bi-matrix games. Finally, numerical example of tourism planning management model is presented to illustrate the methodologies adopted and solution procedure.
\end{abstract}

Index Terms: Rough interval, Trust measure, Bilinear programming, Bi-matrix games.

(C) 2019 Published by MECS Publisher. Selection and/or peer review under responsibility of the Research Association of Modern Education and Computer Science

\section{Introduction}

Game theory is applied widely in various areas such as finance, economic aspects, management problems, business, social policy, military, operational research, engineering, biology and international and national politics etc. For details, see $[1,2]$. In numerous practical situations, there are vagueness occur in bi-matrix games, which is due to lack of information about the parameters of bi-matrix games or they are approximately known. In this problem, we suppose uncertainties in the parameters are random or fuzzy parameters. However, numerous surveys have showed that these imprecise parameters are neither fuzzy nor random. This drives a new class of continuous differential games defined as rough bi-matrix games, such that the bi-matrix games

* Corresponding author.

E-mail address: 
parameters are rough variables. Most scholars considered matrix game with imprecision parameters, such as, Harsanyi [3] made an important contribution in dealing with the probabilistic nature imprecision in games by developing Bayesian games theory. $\mathrm{Xu}$ [4] use linear programming technique to debate zero-sum two-person game with payoffs given as grey numbers. Dhingra et al. [5] combined the fuzzy set theory with cooperative game to yield a novel optimization technique to define as cooperative fuzzy games and give a computational method to find the optimal solutions of multiple objective programming problems. Takahashi [6], analyzed zero-sum two-person matrix game under random environment. Then Espin et al. [7] discussed an innovative approach depend on fuzzy logic to construe n-person cooperative games and experimentally and theoretically studied the results by giving three-case studies.

Rough set theory has a large application in different fields such as knowledge acquisition, decision analysis, machine learning, civil engineering problems and decision algorithms etc. For details, see [9, 10, 11, 12]. Robolledo [13] in his research given the basic concept and definitions of rough intervals. The special advantage of rough intervals (RIs) is that it can deal with the partially ill-defined or unknown variables, the rough intervals are also able to model continuous parameters and satisfies all properties and basic concepts of rough sets such as the lower and upper approximation concepts. The approach for obtaining the solution of rough programming problem is to transform problem from rough interval to crisp using crisp evaluation theorem. The satisfaction level of rough set is defined using the level of confidence $\alpha \in[0,1]$. The level of satisfaction is exact when $\alpha=1$, and complementary when $\alpha=0$. When $\alpha \in(0,1)$, the rough set theory assumes that it satisfies the level of confidence $\alpha$ measured by the trust level, as given by Liu [14].

In reality, the parameters involved in bi-matrix games may be uncertain and rough in nature. For example, the sales amount of a company is given by rough interval [(200,300):(170,320)] which mean that the sales amount varies within the variable ranges from 200 to 300 units in most cases and, in some special periods, the range may vary from 170 units to 320 units when the company use the strategy of advertisement.

The objective of the current paper is to discuss a novel method for solving the rough interval bi-matrix games. In this methodology, the values of the players and the optimal strategies of the rough bi-matrix games are obtained as rough intervals, where the decision makers feel relax to make a decision in a range which we called in this article as 'solution space'. The uncertainties in such problems are measured using the trust measure of rough intervals. We also obtain the optimal solution of the rough bi-matrix games using the expected value operator and the trust measure of rough interval.

The present paper is organized as follows. In Section 2, we introduce literature review about bi-matrix games. In Section 3, some necessary definition and preliminary are given. In section 4, we introduce bi-matrix games and its properties. In section 5, we introduce bi-matrix game under rough interval environment and we present our proposed method for solving rough bi-matrix game. In Section 6, we transform the rough bilinear programming problem to a crisp bilinear programming problem using trust measure of rough interval. Finally, in section 7, numerical example of tourism planning management model is given to illustrate our results.

\section{Related Works}

In recent years, a lot of endeavors have been done to expand the crisp bi-matrix games concept to uncertain and fuzzy bi-matrix games. Prasanta Mula et al [15] have proposed bi-rough programming approach for solving bi-matrix games with bi-rough payoff elements. Reference [16] discussed fuzzy based GA for entropy bimatrix goal game. Chandan et al [17] explored fuzzy based GA to multi-objective entropy bi-matrix game. Wei Fei et al [18] introduced bilinear programming approach to solve interval bi-matrix games in tourism planning management. The authors in [19] analyzed credibilistic bi-matrix game with asymmetric information: bayesian optimistic equilibrium strategy. [20] studied the imprecise matrix games with triangular intuitionistic fuzzy numbers environment. Also, [21] discussed game theory with fuzzy set theory and multi-criteria decision making. [22] viewed on the solution of matrix games with generalised trapezoidal fuzzy payoffs. [23] viewed on the solution of matrix game with I-fuzzy payoffs. [24] analyzed the soft games probabilistic equilibrium solution. [25] discussed bi-matrix game under bi-fuzzy environment. [26] discussed dual hesitant fuzzy matrix 
games based on new similarity measure. [27] studied intelligent water management with triangular type-2 intuitionistic fuzzy matrix games approach. Reference [28] investigated the solution of bi-matrix games with fuzzy payoffs by introducing Nature as a third player. Jinwu Gao [29] studied the uncertain bi-matrix game with applications. Sankar Kumar Roy [30] discussed bi-matrix game under rough set approach. However, the method of solving bi-matrix game with rough intervals payoffs that discussed in this article is completely different from that of Sankar Kumar Roy, in our methodology the values of the players and the optimal strategies of rough bi-matrix games are obtained as rough intervals, where the decision makers feels relax to make decision in a range which we called in this article as 'solution space'.

\section{Preliminaries}

As this paper is mainly based on rough interval (RI) so we recall the basic knowledge of rough set theory. In this section we are discuss some basic knowledge and properties of rough set theory that are need to develop the paper and easily understandable.

\subsection{Rough set}

Rough set theory was initialized by [8]. It has been well applied and developed in a wide variety of uncertainty real models.

Definition 1: [8] Let $\Theta$ be the universal set, $\mathcal{R}$ be the equivalence relation on $\boldsymbol{\Theta},[\theta]_{\mathcal{R}}$ be the set of equivalence class of $\mathcal{R}$ and $\boldsymbol{\Omega}$ be a nonempty subset of $\boldsymbol{\Theta}$. The upper and lower approximations of the set $\boldsymbol{\Omega}$ are defined as,

$$
\begin{gathered}
\overline{\mathcal{R} \boldsymbol{\Omega}}=\left\{\theta \in \boldsymbol{\Theta}:[\theta]_{\mathcal{R}} \cap \boldsymbol{\Omega} \neq \phi\right\} \\
\underline{\mathcal{R} \boldsymbol{\Omega}}=\left\{\theta \in \boldsymbol{\Theta}:[\theta]_{\mathcal{R}} \subseteq \boldsymbol{\Omega}\right\} \\
\aleph \boldsymbol{\Omega}=\overline{\mathcal{R} \boldsymbol{\Omega}}-\underline{\mathcal{R} \boldsymbol{\Omega}}
\end{gathered}
$$

If $\boldsymbol{\kappa} \boldsymbol{\Omega} \neq \phi$, then set $\boldsymbol{\Omega}$ is called rough set.

Definition 2: The collection of all sets having the same upper and lower approximations is called a rough set, denoted by $(\overline{\mathcal{R} \Omega}, \underline{\mathcal{R} \Omega})$.

Definition 3: Let $\boldsymbol{\Omega}$ be a nonempty subset of $\boldsymbol{\Theta}, \Lambda$ is a $\sigma$-algebra of $\boldsymbol{\Omega}, \theta$ an element in $\boldsymbol{\Lambda}$, and $\pi$ a nonnegative , real-valued, additive set function. Then $(\Omega, \theta, \Lambda, \pi)$ is called a rough space.

Definition 4: The rough variable $\xi^{R}$ is a function from rough space $(\boldsymbol{\Omega}, \theta, \boldsymbol{\Lambda}, \pi)$ to the set of real numbers. Let $\xi^{-(\mathrm{LAI})}, \xi^{+(\mathrm{LAI})}, \xi^{-(\mathrm{UAI})}$ and $\xi^{+(\mathrm{UAI})}$ are any real numbers such that $\xi^{-(\mathrm{UAI})} \leq \xi^{-(\mathrm{LAI})} \leq \xi^{+(\mathrm{LAI})} \leq \xi^{+(\mathrm{UAI})}$ and $\xi^{R}=\left[\left(\xi^{-(\mathrm{LAI})}, \xi^{+(\mathrm{LAI})}\right):\left(\xi^{-(\mathrm{UAI})}, \xi^{+(\mathrm{UAI})}\right)\right]$ is called a rough variable if,

$\left\{\begin{array}{c}\xi^{-(\mathrm{LAI})} \leq \xi^{R}(\theta) \leq \xi^{+(\mathrm{LAI})}, \quad \text { iff } \theta \in \underline{\mathcal{R} \Omega}, \quad \text { for exact case. } \\ \xi^{-(\mathrm{UAI})} \leq \xi^{R}(\theta) \leq \xi^{-(\mathrm{LAI})} \text { or } \xi^{+(\mathrm{LAI})} \leq \xi^{R}(\theta) \leq \xi^{+(\mathrm{UAI})}, \quad \text { iff } \theta \in \kappa \boldsymbol{\Omega},\end{array}\right.$

Definition 5: [14] Let $\operatorname{Tr}$ be the trust which is a measure on rough space. The measure $\operatorname{Tr}$ is defined on a set $\mathrm{A} \in \boldsymbol{\Lambda}$ 


$$
\operatorname{Tr}\{\mathbf{A}\}=\frac{1}{2}(\overline{\operatorname{Tr}}\{\mathbf{A}\}+\underline{\operatorname{Tr}}\{\mathbf{A}\})
$$

Where $\overline{\operatorname{Tr}}\{\mathbf{A}\}=\frac{\pi\{\mathbf{A}\}}{\pi\{\boldsymbol{\Omega}\}}$ and $\underline{\operatorname{Tr}}\{\mathbf{A}\}=\frac{\pi\{\mathbf{A} \cap \boldsymbol{\theta}\}}{\pi\{\boldsymbol{\theta}\}}$.

Definition 6: [14] Let $\xi^{R}=\left[\left(\xi^{-(\mathrm{LAI})}, \xi^{+(\mathrm{LAI})}\right):\left(\xi^{-(\mathrm{UAI})}, \xi^{+(\mathrm{UAI})}\right)\right]$ be a rough variable such that $\xi^{-(\mathrm{UAI})} \leq$ $\xi^{-(\mathrm{LAI})} \leq \xi^{+(\mathrm{LAI})} \leq \xi^{+(\mathrm{UAI})}$, then the trust measure of the rough value $\xi^{R} \leq \beta$ is defined as

$$
\begin{aligned}
& \left(\begin{array}{cl}
0, & \text { if } \beta \leq \xi^{-(\mathrm{UAI})} \\
\frac{1}{2}\left(\frac{\xi^{-(\mathrm{UAI})}-\beta}{\xi^{-(\mathrm{UAI})}-\xi^{+(\mathrm{UAI})}}\right), & \text { if } \xi^{-(\mathrm{UAI})} \leq \beta \leq \xi^{-(\mathrm{LAI})}
\end{array}\right.
\end{aligned}
$$

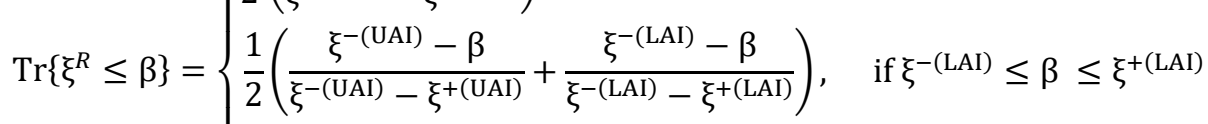

$$
\begin{aligned}
& \frac{1}{2}\left(\frac{\xi^{-(\mathrm{UAI})}-\beta}{\xi^{-(\mathrm{UAI})}-\xi^{+(\mathrm{UAI})}}+1\right), \quad \quad \text { if } \xi^{+(\mathrm{LAI})} \leq \beta \leq \xi^{+(\mathrm{UAI})} \\
& 1 \text {, } \\
& \text { if } \beta \geq \xi^{+(\mathrm{UAI})}
\end{aligned}
$$

and the $\alpha$-pessimistic value of $\xi^{R}$ is,

$\xi^{R}{ }_{\text {inf }}(\alpha)=\inf \left\{\beta: \operatorname{Tr}\left\{\xi^{R} \leq \beta\right\} \geq \alpha\right\}$

$$
=\left\{\begin{array}{cc}
(1-2 \alpha) \xi^{-(\mathrm{UAI})}+2 \alpha \xi^{+(\mathrm{UAI})}, & \text { if } \alpha \leq \frac{\xi^{-(\mathrm{LAI})}-\xi^{-(\mathrm{UAI})}}{2\left(\xi^{+(\mathrm{UAI})}-\xi^{-(\mathrm{UAI})}\right)} \\
2(1-\alpha) \xi^{-(\mathrm{UAI})}+(2 \alpha-1) \xi^{+(\mathrm{UAI})}, & \text { if } \alpha \geq \frac{\xi^{+(\mathrm{LAI})}+\xi^{+(\mathrm{UAI})}-2 \xi^{-(\mathrm{UAI})}}{2\left(\xi^{+(\mathrm{UAI})}-\xi^{-(\mathrm{UAI})}\right)} \\
\frac{\xi^{-(\mathrm{UAI})}\left(\xi^{+(\mathrm{LAI})}-\xi^{-(\mathrm{LAI})}\right)+\xi^{-(\mathrm{LAI})}\left(\xi^{+(\mathrm{UAI})}-\xi^{-(\mathrm{UAI})}\right)+2 \alpha\left(\xi^{+(\mathrm{LAI})}-\xi^{-(\mathrm{LAI})}\right)\left(\xi^{+(\mathrm{UAI})}-\xi^{-(\mathrm{UAI})}\right)}{\left(\xi^{+(\mathrm{LAI})}-\xi^{-(\mathrm{LAI})}\right)+\left(\xi^{+(\mathrm{UAI})}-\xi^{-(\mathrm{UAI})}\right)}, \text { otherwise }
\end{array}\right.
$$

Theorem 1: [31] Let $\xi^{R}=\left[\left(\xi^{-(\mathrm{LAI})}, \xi^{+(\mathrm{LAI})}\right):\left(\xi^{-(\mathrm{UAI})}, \xi^{+(\mathrm{UAI})}\right)\right]$ be a rough interval parameter such that $\xi^{-(\mathrm{UAI})} \leq \xi^{-(\mathrm{LAI})} \leq \xi^{+(\mathrm{LAI})} \leq \xi^{+(\mathrm{UAI})}$ and $\mathrm{Tr}$ be the trust measure which measured on the rough interval space. For a given confidence level $\alpha \in(0,1)$,

(1) when $\alpha \leq \frac{\xi^{-(\mathrm{LAI})}-\xi^{-(\mathrm{UAI})}}{2\left(\xi^{+(\mathrm{UAI})}-\xi^{-(\mathrm{UAI})}\right)}, \operatorname{Tr}\left\{\xi^{R} \leq 0\right\} \geq \alpha$, if and only if,

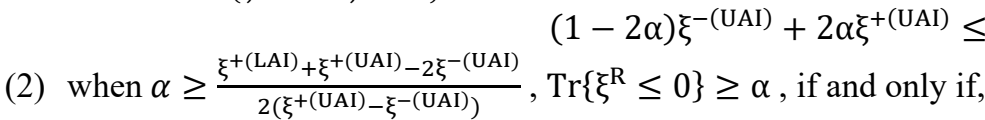

$2(1-\alpha) \xi^{-(\mathrm{UAI})}+(2 \alpha-1) \xi^{+(\mathrm{UAI})} \leq 0$

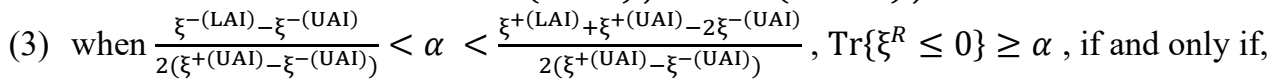
$\frac{2 \alpha \xi^{+(\mathrm{LAI})} \xi^{+(\mathrm{UAI})}+(1-2 \alpha) \xi^{-(\mathrm{LAI})} \xi^{+(\mathrm{UAI})}+(1-2 \alpha) \xi^{(\mathrm{LAI})} \xi^{-(\mathrm{UAI})}+2(\alpha-1) \xi^{-(\mathrm{LAI})} \xi^{-(\mathrm{UAI})}}{\left(\xi^{+(\mathrm{LAI})}-\xi^{-(\mathrm{LAI})}\right)+\left(\xi^{+(\mathrm{UAI})} \xi^{-(\mathrm{UAI})}\right)} \leq 0$

Theorem 2: [31] Let $\xi^{R}{ }_{k}=\left[\left(\xi_{k}{ }^{-(\mathrm{LAI})}, \xi_{k}{ }^{+(\mathrm{LAI})}\right):\left(\xi_{k}{ }^{-(\mathrm{UAI})}, \xi_{k}{ }^{+(\mathrm{UAI})}\right)\right]$ are rough interval variables for $\mathrm{k}=$ $1,2, \ldots, \mathrm{m}$ and a function $\mathrm{F}\left(\mathrm{x}, \xi^{R}\right)$ can be written as,

$$
\mathrm{F}\left(\mathrm{x}, \xi^{R}\right)=\mathrm{f}_{1}(x) \xi_{1}^{R}+\mathrm{f}_{2}(x) \xi_{2}^{R}+\cdots+\mathrm{f}_{m}(x) \xi_{m}^{R}+\mathrm{f}_{0}(x) .
$$

If $\mathrm{f}_{k}(x)$ be a nonnegative real function. Then there exists a level confidence $\alpha \in(0,1)$, such that,

(1) when $\alpha \leq \frac{\xi_{k}^{-(\mathrm{LAI})}-\xi_{k}^{-(\mathrm{UAI})}}{2\left(\xi_{k}{ }^{+\mathrm{UAI})}-\xi_{k}^{-(\mathrm{UAI})}\right)}$, defined, 
(2) when $\alpha \geq \frac{\xi_{k}{ }^{+(\mathrm{LAI})}+\xi_{k}{ }^{+(\mathrm{UAI})}-2 \xi_{k}^{-(\mathrm{UAI})}}{2\left(\xi_{k}{ }^{+\mathrm{UAI})}-\xi_{k}{ }^{-(\mathrm{UAI})}\right)}$, defined,

$$
\mathrm{s}_{k}=(1-2 \alpha) \xi_{k}^{-(\mathrm{UAI})}+2 \alpha \xi_{k}{ }^{+(\mathrm{UAI})}
$$

$$
\mathrm{s}_{k}=2(1-\alpha) \xi_{k}^{-(\mathrm{UAI})}+(2 \alpha-1) \xi_{k}^{+(\mathrm{UAI})}
$$

(3) when $\frac{\xi_{k}{ }^{-(\mathrm{LAI})}-\xi_{k}{ }^{-(\mathrm{UAI})}}{2\left(\xi_{k}{ }^{+(\mathrm{UAI})}-\xi_{k}{ }^{-\mathrm{UAI})}\right)}<\alpha<\frac{\xi_{k}{ }^{+(\mathrm{LAI})}+\xi_{k}{ }^{+(\mathrm{UAI})}-2 \xi_{k}^{-(\mathrm{UAI})}}{2\left(\xi_{k}{ }^{+(\mathrm{UAI})}-\xi_{k}{ }^{-(\mathrm{UAI})}\right)}$, defined, $\mathrm{s}_{k}=\frac{2 \alpha \xi_{k}{ }^{+(\mathrm{LAI})} \xi_{k}{ }^{+(\mathrm{UAI})}+(1-2 \alpha) \xi_{k}{ }^{-(\mathrm{LAI})} \xi_{k}{ }^{+(\mathrm{UAI})}+(1-2 \alpha) \xi_{k}{ }^{+\mathrm{LAI})} \xi_{k}{ }^{-(\mathrm{UAI})}+2(\alpha-1) \xi_{k}{ }^{-(\mathrm{LAI})} \xi_{k}{ }^{-(\mathrm{UAI})}}{\left(\xi_{k}{ }^{+(\mathrm{LAI})}-\xi_{k}{ }^{-(\mathrm{LAI})}\right)+\left(\xi_{k}{ }^{+(\mathrm{UAI})}-\xi_{k}{ }^{-(\mathrm{UAI})}\right)}$

Then for a confidence level $\alpha \in(0,1)$, the rough measure $\operatorname{Tr}\left\{\mathrm{F}\left(\mathrm{x}, \xi^{R}\right) \leq 0\right\} \geq \alpha$ if and only if $\mathrm{F}\left(\mathrm{x}, \xi^{R}\right)=$ $\sum_{k=1}^{n} \mathrm{~s}_{k} \mathrm{f}_{k}(x)+\mathrm{f}_{0}(x) \leq 0$.

Definition 7: Let $\xi^{R}$ be a rough variable, the expected value of $\xi^{R}$ is defined by

$$
E\left[\xi^{R}\right]=\int_{0}^{\infty} \operatorname{Tr}\left\{\xi^{R} \geq \mathrm{x}\right\} d x-\int_{-\infty}^{0} \operatorname{Tr}\left\{\xi^{R} \leq \mathrm{x}\right\} d x
$$

provided that at least one of the two integrals is finite.

Theorem 3: [32] Let $\xi^{R}=\left[\left(\xi^{-(\mathrm{LAI})}, \xi^{+(\mathrm{LAI})}\right):\left(\xi^{-(\mathrm{UAI})}, \xi^{+(\mathrm{UAI})}\right)\right]$ where $\xi^{-(\mathrm{UAI})} \leq \xi^{-(\mathrm{LAI})} \leq \xi^{+(\mathrm{LAI})} \leq \xi^{+(\mathrm{UAI})}$ be a rough interval. Then the expected value of $\xi^{R}$ is $\mathrm{E}\left(\xi^{R}\right)=\frac{1}{2}\left[\mu\left(\xi^{-(\mathrm{LAI})}+\xi^{+(\mathrm{LAI})}\right)+(1-\mu)\left(\xi^{-(\mathrm{UAI})}+\right.\right.$ $\left.\left.\xi^{+(\mathrm{UAI})}\right)\right]$.

Remark 1: If $\mu=0.5$; then the expected value of $\xi^{R}$ is $\mathrm{E}\left(\xi^{R}\right)=\frac{1}{4}\left[\xi^{-(\mathrm{LAI})}+\xi^{+(\mathrm{LAI})}+\xi^{-(\mathrm{UAI})}+\xi^{+(\mathrm{UAI})}\right]$.

\section{The classical bi-matrix games}

Suppose that $\mathrm{S}_{1}=\left\{\gamma_{1}, \gamma_{2}, \ldots, \gamma_{m}\right\}$ and $\mathrm{S}_{2}=\left\{\rho_{1}, \rho_{2}, \ldots, \rho_{n}\right\}$ be the sets of pure strategies for players I and II, respectively. The payoff matrices of players I and II are given as $\mathbf{D}=\left(d_{i j}\right)_{m \times n}$ and $\mathbf{E}=\left(e_{i j}\right)_{m \times n}$, the mixed strategies of players I and II are given by the vectors $\mathbf{p}=\left(\mathrm{p}_{1}, \mathrm{p}_{2}, \ldots ., \mathrm{p}_{\mathrm{m}}\right)^{\mathrm{T}}$ and $\mathbf{q}=\left(\mathrm{q}_{1}, \mathrm{q}_{2}, \ldots ., \mathrm{q}_{\mathrm{n}}\right)^{\mathrm{T}}$, where $\mathrm{p}_{\mathrm{i}}(i=1,2, \ldots, m)$ and $\mathrm{q}_{\mathrm{j}}(j=1,2, \ldots, n)$ are the probabilities that players I and II select their pure strategies $\gamma_{i} \in \mathrm{S}_{1}$ and $\rho_{i} \in \mathrm{S}_{2}$, respectively. Let $\mathbf{P}=\left\{\mathbf{p}: \sum_{i=1}^{m} \mathrm{p}_{i}=1, \mathrm{p}_{i} \geq 0(i=1,2, \ldots, m)\right\}$ and $\mathbf{Q}=$ $\left\{\mathbf{q}: \sum_{i=1}^{m} \mathrm{q}_{\mathrm{j}}=1, \mathrm{q}_{\mathrm{j}} \geq 0(j=1,2, \ldots, n)\right\}$ express the sets of mixed strategies for player I and II, respectively.

Suppose that the two players need to maximize their own payoffs. So, the bi-matrix game is given by $\mathbf{G}=$ $\{\mathbf{P}, \mathbf{Q}, \mathbf{D}, \mathbf{E}\}$, which is called a bimatrix game (D, E).

The expected payoffs for a bi-matrix game (D,E), when players I and II select mixed strategies $\mathbf{p} \in \mathbf{P}$ and $\mathbf{q} \in \mathbf{Q}$ can be expressed as follows:

$\mathbf{E}_{\mathbf{1}}(\mathbf{p}, \mathbf{q}, \mathbf{D})=\mathbf{p}^{T} \mathbf{D q}=\sum_{\mathrm{i}=1}^{\mathrm{m}} \sum_{\mathrm{j}=1}^{\mathrm{n}} \mathrm{p}_{i} \mathrm{~d}_{i j} \mathrm{q}_{j}$

And

$\mathbf{E}_{2}(\mathbf{p}, \mathbf{q}, \mathbf{E})=\mathbf{p}^{T} \mathbf{E} \mathbf{q}=\sum_{\mathrm{i}=1}^{\mathrm{m}} \sum_{\mathrm{j}=1}^{\mathrm{n}} \mathrm{p}_{i} \mathrm{e}_{i j} \mathrm{q}_{j}$.

Definition 8: If $\left(\mathbf{p}^{*}, \mathbf{q}^{*}\right) \in(\mathrm{P} \times \mathrm{Q})$ satisfies the following conditions 
and

$$
\mathbf{p}^{\mathrm{T}} \mathbf{D} \mathbf{q}^{*} \leq \mathbf{p}^{* \mathrm{~T}} \mathbf{D} \mathbf{q}^{*}
$$

$$
\mathbf{p}^{* T} \mathbf{E q} \leq \mathbf{p}^{* T} \mathbf{E q}^{*}
$$

For mixed strategies $\mathbf{p} \in \mathbf{P}$ and $\mathbf{q} \in \mathbf{Q}$, then $\left(\mathbf{p}^{*}, \mathbf{q}^{*}\right)$ is called the equilibrium solution for bi-matrix game (D, E), $\mathbf{p}^{*}$ and $\mathbf{q}^{*}$ are called the optimal strategies of players I and II, $\mathbf{u}^{*}=\mathbf{p}^{* T} \mathbf{D} \mathbf{q}^{*}$ and $\mathbf{v}^{*}=\mathbf{p}^{* T} \mathbf{E} \mathbf{q}^{*}$ are called the equilibrium value of players I and II, respectively.

Theorem 4: $\left(\mathbf{p}^{*}, \mathbf{q}^{*}\right)$ is the equilibrium solution of bimatrix game (D, E)in the sense of mixed strategies if and only if it is optimal solution of bilinear programming problems expressed as follows:

The proof of Theorem 4 can be found in [18]

$$
\begin{gathered}
\max \left\{\mathbf{p}^{\mathbf{T}} \mathbf{D} \mathbf{q}+\mathbf{p}^{\mathbf{T}} \mathbf{E} \mathbf{q}-\mathrm{u}-\mathrm{v}\right\} \\
\text { s.t. }\left\{\begin{array}{c}
\mathbf{D} \mathbf{q} \leq \mathrm{u} \mathrm{e}^{m} \\
\mathbf{E}^{\mathbf{T}} \mathbf{p} \leq \mathrm{ve}^{n} \\
\mathbf{p}^{\mathbf{T}} \mathrm{e}^{m}=\mathbf{1} \\
\mathbf{q}^{\mathbf{T}} \mathrm{e}^{n}=\mathbf{1} \\
\mathbf{p} \geq \mathbf{0} \\
\mathbf{q} \geq \mathbf{0} \\
\text { u,v unrestricted in sign }
\end{array}\right.
\end{gathered}
$$

\section{Approach 1: Bilinear programming approach for solving rough bi-matrix games}

Without loss of generality, suppose that the payoff matrices of players I and II, respectively, expressed by $\mathbf{D}^{\mathrm{R}}=\left(\mathbf{D}^{\mathrm{R}}{ }_{i j}\right)_{m \times n}=\left(\left[\left(\mathrm{d}_{i j}{ }^{-(\mathrm{LAI})}, \mathrm{d}_{i j}{ }^{+(\mathrm{LAI})}\right):\left(\mathrm{d}_{i j}{ }^{-(\mathrm{UAI})}, \mathrm{d}_{i j}{ }^{+(\mathrm{UAI})}\right)\right]\right)_{m \times n}$ and $\mathbf{E}^{\mathrm{R}}=\left(\mathbf{E}^{\mathrm{R}}{ }_{i j}\right)_{m \times n}=\left(\left[\left(\mathrm{e}_{i j}{ }^{-(\mathrm{LAI})}, \mathrm{e}_{i j}{ }^{+(\mathrm{LAI})}\right):\left(\mathrm{e}_{i j}{ }^{-(\mathrm{UAI})}, \mathrm{e}_{i j}{ }^{+(\mathrm{UAI})}\right)\right]\right)_{m \times n}$, where $\mathbf{D}^{\mathrm{R}}=\left(\mathbf{D}^{\mathrm{R}}{ }_{i j}\right)_{m \times n}$ and $\mathbf{E}^{\mathrm{R}}=\left(\mathbf{E}^{\mathrm{R}}{ }_{i j}\right)_{m \times n}(i=1,2, \ldots, m ; j=1,2, \ldots, n)$ are rough intervals payoffs; $\mathrm{d}_{i j}{ }^{-(\mathrm{LAI})}$ is the lower lower bound of rough interval $\mathbf{D}^{\mathrm{R}}{ }_{i j}, \mathrm{~d}_{i j}{ }^{+(\mathrm{LAI})}$ is the upper lower bound of rough interval $\mathbf{D}^{\mathrm{R}}{ }_{i j}, \mathrm{~d}_{i j}{ }^{-(\mathrm{UAI})}$ is the lower upper bound of rough interval $\mathbf{D}^{\mathrm{R}}{ }_{i j}$ and $\mathrm{d}_{i j}{ }^{+(\mathrm{UAI})}$ is the upper upper bound of rough interval $\mathbf{D}^{\mathrm{R}}{ }_{i j}, \mathrm{e}_{i j}{ }^{-(\mathrm{LAI})}$ is the lower lower bound of rough interval $\mathbf{E}^{\mathrm{R}}{ }_{i j}, \mathrm{e}_{i j}{ }^{+(\mathrm{LAI})}$ is the upper lower bound of rough interval $\mathbf{E}^{\mathrm{R}}{ }_{i j}, \mathrm{e}_{i j}{ }^{-(\mathrm{UAI})}$ is the lower upper bound of rough interval $\mathbf{E}^{\mathrm{R}}{ }_{i j}$ and $\mathrm{e}_{i j}{ }^{+(\mathrm{UAI})}$ is the upper upper bound of rough interval $\mathbf{E}^{\mathrm{R}}{ }_{i j}$. The mixed strategy $\mathbf{P}$ and $\mathbf{Q}$ and pure strategy $\mathrm{S}_{1}$ and $\mathrm{S}_{2}$ for player I and player II are given as defined in section 3 . For short the rough interval bi-matrix game can be denoted by $\left(\mathbf{D}^{\mathrm{R}}, \mathbf{E}^{\mathrm{R}}\right)$.

By taking the value $\left(\mathrm{d}_{i j} \times \mathrm{e}_{i j}\right) \in \mathbf{D}^{\mathrm{R}}{ }_{i j} \times \mathbf{E}^{\mathrm{R}}{ }_{i j}(\mathrm{i}=1,2, \ldots, \mathrm{m} ; \mathrm{j}=1,2, \ldots, \mathrm{n})$, we build a bimatrix game (D, E), where the matrices $\mathbf{D}=\left(d_{i j}\right)_{m \times n}$ and $\mathbf{E}=\left(e_{i j}\right)_{m \times n}$. It is clear that from Eqs. (1) and (2), the value u of player I is a function of $d_{i j}$ in the rough interval payoffs $\mathbf{D}^{\mathrm{R}}$, given by $\mathrm{u}=\mathrm{u}\left(\left(\mathrm{d}_{i j}\right)\right)$. Also, the corresponding optimal strategy $\mathbf{p}^{*} \in \mathbf{P}$ of player I is a function of $d_{i j}$, given by $\mathbf{p}^{*}=\mathbf{p}^{*}\left(\left(\mathrm{~d}_{i j}\right)\right)$. Similarly, the value $\mathrm{v}$ of player II is a function of $e_{i j}$ in the rough interval payoffs $\mathbf{E}^{\mathrm{R}}$, given by $\mathrm{v}=\mathrm{v}\left(\left(\mathrm{e}_{i j}\right)\right)$. Also, the corresponding optimal strategy $\mathbf{q}^{*} \in \mathbf{Q}$ of player II is a function of $e_{i j}$, given by $\mathbf{q}^{*}=\mathbf{q}^{*}\left(\left(\mathrm{e}_{i j}\right)\right)$.

So Eqs. (3) can be written in the following corresponding rough interval programming problems as follow: 


$$
\begin{gathered}
\max \left\{\mathbf{p}^{\mathrm{T}} \mathbf{D}^{\mathrm{R}} \mathbf{q}+\mathbf{p}^{\mathrm{T}} \mathbf{E}^{\mathrm{R}} \mathbf{q}-\mathrm{u}-\mathrm{v}\right\} \\
\text { s.t. }\left\{\begin{array}{c}
\mathbf{D}^{\mathrm{R}} \mathbf{q} \leq \mathrm{u} \mathrm{e}^{m} \\
\left(\mathbf{E}^{\mathrm{R}}\right)^{\mathrm{T}} \mathbf{p} \leq \mathrm{v} \mathrm{e}^{n} \\
\mathbf{p}^{\mathrm{T}} \mathrm{e}^{m}=\mathbf{1} \\
\mathbf{q}^{\mathrm{T}} \mathrm{e}^{n}=\mathbf{1} \\
\mathbf{p} \geq \mathbf{0} \\
\mathbf{q} \geq \mathbf{0} \\
\text { u, v unrestricted in sign }
\end{array}\right.
\end{gathered}
$$

The lower lower bound $\mathrm{u}^{-(\mathrm{LAI})}$ and $\mathrm{v}^{-(\mathrm{LAI})}$ of the rough interval values of players $\mathrm{I}$ and $\mathrm{II}$ in the rough interval bi-matrix game $\left(\mathbf{D}^{\mathrm{R}}, \mathbf{E}^{\mathrm{R}}\right)$ and the corresponding optimal strategies $\mathbf{p}^{*-(\mathrm{LAI})} \in \mathbf{P}$ and $\mathbf{q}^{*-(\mathrm{LAI})} \in \mathbf{Q}$ are $\mathrm{u}^{-(\mathrm{LAI})}=\mathrm{u}\left(\left(\mathrm{d}_{i j}{ }^{-(\mathrm{LAI})}\right)\right) \quad, \quad \mathrm{v}^{-(\mathrm{LAI})}=\mathrm{v}\left(\left(\mathrm{e}_{i j}{ }^{-(\mathrm{LAI})}\right)\right) \quad, \quad \mathbf{p}^{*-(\mathrm{LAI})}=\mathbf{p}^{*}\left(\left(\mathrm{~d}_{i j}{ }^{-(\mathrm{LAI})}\right)\right) \quad$ and $\mathbf{q}^{*-(\mathrm{LAI})}=\mathbf{q}^{*}\left(\left(\mathrm{e}_{i j}{ }^{-(\mathrm{LAI})}\right)\right)$, respectively. From Eq. (3), $\left(\mathbf{p}^{*-(\mathrm{LAI})}, \mathbf{q}^{*-(\mathrm{LAI})}\right)$ is the optimal solution of the following bilinear programming problem:

\section{Model 1}

$$
\begin{array}{r}
\max \left\{\left(\mathbf{p}^{-(\mathrm{LAI})}\right)^{\mathbf{T}} \mathbf{D}^{-(\mathrm{LAI})} \mathbf{q}^{-(\mathrm{LAI})}+\left(\mathbf{p}^{-(\mathrm{LAI})}\right)^{\mathbf{T}} \mathbf{E}^{-(\mathrm{LAI})} \mathbf{q}^{-(\mathrm{LAI})}-\mathrm{u}^{-(\mathrm{LAI})}-\mathrm{v}^{-(\mathrm{LAI})}\right\} \\
\text { s.t. }\left\{\begin{array}{c}
\mathbf{D}^{-(\mathrm{LAI})} \mathbf{q}^{-(\mathrm{LAI})} \leq \mathrm{u}^{-(\mathrm{LAI})} \mathrm{e}^{m} \\
\left(\mathbf{E}^{-(\mathrm{LAI})}\right)^{\mathbf{T}} \mathbf{p}^{-(\mathrm{LAI})} \leq \mathrm{v}^{-(\mathrm{LAI})} \mathrm{e}^{n} \\
\left(\mathbf{p}^{-(\mathrm{LAI})}\right)^{\mathbf{T}} \mathrm{e}^{m}=\mathbf{1} \\
\left(\mathbf{q}^{-(\mathrm{LAI})}\right)^{\mathbf{T}} \mathrm{e}^{n}=\mathbf{1} \\
\mathbf{p}^{-(\mathrm{LAI})} \geq \mathbf{0} \\
\mathbf{q}^{-(\mathrm{LAI})} \geq \mathbf{0} \\
\mathrm{u}^{-(\mathrm{LAI})}, \mathrm{v}^{-(\mathrm{LAI})} \text { unrestricted in sign }
\end{array}\right.
\end{array}
$$

The optimal solution of Eq. (5) $\left(\mathbf{p}^{*-(\mathbf{L A I})}, \mathbf{q}^{*-(\mathbf{L A I})}, \mathbf{u}^{-(\mathbf{L A I})}, \mathbf{v}^{-(\mathbf{L A I})}\right)$ can be obtained by using the Lingo software. Then, we get the lower lower bound $\mathbf{u}^{-(\mathbf{L A I})}$ and $\mathbf{v}^{-(\mathbf{L A I})}$ of the rough interval values of players I and II in the rough interval bimatrix game $\left(\mathbf{D}^{\mathbf{R}}, \mathbf{E}^{\mathbf{R}}\right)$ and the corresponding optimal strategies $\mathbf{p}^{*-(\mathbf{L A I})} \in \mathbf{P}$ and $\mathbf{q}^{*-(\mathbf{L A I})} \in \mathbf{Q}$, respectively.

Similarly, the upper lower bound $\mathrm{u}^{+(\mathrm{LAI})}$ and $\mathrm{v}^{+(\mathrm{LAI})}$ of the rough interval values of players I and II in the rough interval bi-matrix game $\left(\mathbf{D}^{\mathrm{R}}, \mathbf{E}^{\mathrm{R}}\right)$ and the corresponding optimal strategies $\mathbf{p}^{*+(\mathrm{LAI})} \in \mathbf{P}$ and $\mathbf{q}^{*+(\mathrm{LAI})} \in \mathbf{Q}$ are $\mathrm{u}^{+(\mathrm{LAI})}=\mathrm{u}\left(\left(\mathrm{d}_{i j}{ }^{+(\mathrm{LAI})}\right)\right), \mathrm{v}^{+(\mathrm{LAI})}=\mathrm{v}\left(\left(\mathrm{e}_{i j}{ }^{+(\mathrm{LAI})}\right)\right), \mathbf{p}^{*+(\mathrm{LAI})}=\mathbf{p}^{*}\left(\left(\mathrm{~d}_{i j}{ }^{+(\mathrm{LAI})}\right)\right)$ and $\mathbf{q}^{*+(\mathrm{LAI})}=$ $\mathbf{q}^{*}\left(\left(\mathrm{e}_{i j}{ }^{+(\mathrm{LAI})}\right)\right)$, respectively. From Eq. (3), $\left(\mathbf{p}^{*+(\mathrm{LAI})}, \mathbf{q}^{*+(\mathrm{LAI})}\right)$ is the optimal solution of the following bilinear programming problem: 


$$
\begin{array}{r}
\max \left\{\left(\mathbf{p}^{+(\mathrm{LAI})}\right)^{\mathrm{T}} \mathbf{D}^{+(\mathrm{LAI})} \mathbf{q}^{+(\mathrm{LAI})}+\left(\mathbf{p}^{+(\mathrm{LAI})}\right)^{\mathrm{T}} \mathbf{E}^{+(\mathrm{LAI})} \mathbf{q}^{+(\mathrm{LAI})}-\mathrm{u}^{+(\mathrm{LAI})}-\mathrm{v}^{+(\mathrm{LAI})}\right\} \\
\text { s.t. }\left\{\begin{array}{c}
\mathbf{D}^{+(\mathrm{LAI})} \mathbf{q}^{+(\mathrm{LAI})} \leq \mathrm{u}^{+(\mathrm{LAI})} \mathrm{e}^{m} \\
\left(\mathbf{E}^{+(\mathrm{LAI})}\right)^{\mathrm{T}} \mathbf{p}^{+(\mathrm{LAI})} \leq \mathrm{v}^{+(\mathrm{LAI})} \mathrm{e}^{n} \\
\left(\mathbf{p}^{+(\mathrm{LAI})}\right)^{\mathrm{T}} \mathrm{e}^{m}=\mathbf{1} \\
\left(\mathbf{q}^{+(\mathrm{LAI})}\right)^{\mathrm{T}} \mathrm{e}^{n}=\mathbf{1} \\
\mathbf{p}^{+(\mathrm{LAI})} \geq \mathbf{0} \\
\mathbf{q}^{+(\mathrm{LAI})} \geq \mathbf{0} \\
\mathrm{u}^{+(\mathrm{LAI})}, \mathrm{v}^{+(\mathrm{LAI})} \text { unrestricted in sign }
\end{array}\right.
\end{array}
$$

The optimal solution of Eq. (6) $\left(\mathbf{p}^{*+(\text { LAI })}, \mathbf{q}^{*+(\text { LAI })}, \mathbf{u}^{+(\mathbf{L A I})}, \mathbf{v}^{+(\mathbf{L A I})}\right)$ can be obtained by using the Lingo software. Then, we get the upper lower bound $\mathbf{u}^{+(\mathbf{L A I})}$ and $\mathbf{v}^{+(\mathbf{L A I})}$ of the rough interval values of players I and II in the rough interval bimatrix game $\left(\mathbf{D}^{\mathbf{R}}, \mathbf{E}^{\mathbf{R}}\right)$ and the corresponding optimal strategies $\mathbf{p}^{*+(\mathbf{L A I})} \in \mathbf{P}$ and $\mathbf{q}^{*+(\mathbf{L A I})} \in \mathbf{Q}$, respectively.

Likewise, the lower upper bound $\mathrm{u}^{-(\mathrm{UAI})}$ and $\mathrm{v}^{-(\mathrm{UAI})}$ of the rough interval values of players I and II in the rough interval bi-matrix game $\left(\mathbf{D}^{\mathrm{R}}, \mathbf{E}^{\mathrm{R}}\right)$ and the corresponding optimal strategies $\mathbf{p}^{*-(\mathrm{UAI})} \in \mathbf{P}$ and $\mathbf{q}^{*-(\mathrm{UAI})} \in$ $\mathbf{Q}$ are $\mathrm{u}^{-(\mathrm{UAI})}=\mathrm{u}\left(\left(\mathrm{d}_{i j}{ }^{-(\mathrm{UAI})}\right)\right), \mathrm{v}^{-(\mathrm{UAI})}=\mathrm{v}\left(\left(\mathrm{e}_{i j}{ }^{-(\mathrm{UAI})}\right)\right), \mathbf{p}^{*-(\mathrm{UAI})}=\mathbf{p}^{*}\left(\left(\mathrm{~d}_{i j}{ }^{-(\mathrm{UAI})}\right)\right)$ and $\mathbf{q}^{*-(\mathrm{UAI})}=$ $\mathbf{q}^{*}\left(\left(\mathrm{e}_{i j}{ }^{-(\mathrm{UAI})}\right)\right)$, respectively. From Eq. (3), $\left(\mathbf{p}^{*-(\mathrm{UAI})}, \mathbf{q}^{*-(\mathrm{UAI})}\right)$ is the optimal solution of the following bilinear programming problem:

\section{Model 3}

$$
\begin{array}{r}
\max \left\{\left(\mathbf{p}^{-(\mathrm{UAI})}\right)^{\mathbf{T}} \mathbf{D}^{-(\mathrm{UAI})} \mathbf{q}^{-(\mathrm{UAI})}+\left(\mathbf{p}^{-(\mathrm{UAI})}\right)^{\mathbf{T}} \mathbf{E}^{-(\mathrm{UAI})} \mathbf{q}^{-(\mathrm{UAI})}-\mathrm{u}^{-(\mathrm{UAI})}-\mathrm{v}^{-(\mathrm{UAI})}\right\} \\
\text { s.t. }\left\{\begin{array}{c}
\mathbf{D}^{-(\mathrm{UAI})} \mathbf{q}^{-(\mathrm{UAI})} \leq \mathrm{u}^{-(\mathrm{UAI})} \mathrm{e}^{m} \\
\left(\mathbf{E}^{-(\mathrm{UAI})}\right)^{\mathbf{T}} \mathbf{p}^{-(\mathrm{UAI})} \leq \mathrm{v}^{-(\mathrm{UAI})} \mathrm{e}^{n} \\
\left(\mathbf{p}^{-(\mathrm{UAI})}\right)^{\mathbf{T}} \mathrm{e}^{m}=\mathbf{1} \\
\left(\mathbf{q}^{-(\mathrm{UAI})}\right)^{\mathbf{T}} \mathrm{e}^{n}=\mathbf{1} \\
\mathbf{p}^{-(\mathrm{UAI})} \geq \mathbf{0} \\
\mathbf{q}^{-(\mathrm{UAI})} \geq \mathbf{0} \\
\mathrm{u}^{-(\mathrm{UAI})}, \mathrm{v}^{-(\mathrm{UAI})} \text { unrestricted in sign }
\end{array}\right.
\end{array}
$$

The optimal solution of Eq. (7) $\left(\mathbf{p}^{*-(\mathbf{U A I})}, \mathbf{q}^{*-(\mathbf{U A I})}, \mathbf{u}^{-(\mathrm{UAI})}, \mathbf{v}^{-(\mathrm{UAI})}\right)$ can be obtained by using the Lingo software. Then, we get the lower upper bound $\mathbf{u}^{-(\mathrm{UAI})}$ and $\mathbf{v}^{-(\mathrm{UAI})}$ of the rough interval values of players I and II in the rough interval bimatrix game $\left(\mathbf{D}^{\mathbf{R}}, \mathbf{E}^{\mathbf{R}}\right)$ and the corresponding optimal strategies $\mathbf{p}^{*-(\mathbf{U A I})} \in \mathbf{P}$ and $\mathbf{q}^{*-(\mathrm{UAI})} \in \mathbf{Q}$, respectively.

Similarly, the upper upper bound $\mathrm{u}^{+(\mathrm{UAI})}$ and $\mathrm{v}^{+(\mathrm{UAI})}$ of the rough interval values of players I and $\mathrm{II}$ in the rough interval bi-matrix game $\left(\mathbf{D}^{\mathrm{R}}, \mathbf{E}^{\mathrm{R}}\right)$ and the corresponding optimal strategies $\mathbf{p}^{*+(\mathrm{UAI})} \in \mathbf{P}$ and $\mathbf{q}^{*+(\mathrm{UAI})} \in$ 
$\mathbf{Q}$ are $\mathrm{u}^{+(\mathrm{UAI})}=\mathrm{u}\left(\left(\mathrm{d}_{i j}{ }^{+(\mathrm{UAI})}\right)\right), \mathrm{v}^{+(\mathrm{UAI})}=\mathrm{v}\left(\left(\mathrm{e}_{i j}{ }^{+(\mathrm{UAI})}\right)\right), \mathbf{p}^{*+(\mathrm{UAI})}=\mathbf{p}^{*}\left(\left(\mathrm{~d}_{i j}{ }^{+(\mathrm{UAI})}\right)\right)$ and $\mathbf{q}^{*+(\mathrm{UAI})}=$ $\mathbf{q}^{*}\left(\left(\mathrm{e}_{i j}{ }^{+(\mathrm{UAI})}\right)\right)$, respectively. From Eq. (3), $\left(\mathbf{p}^{*+(\mathrm{UAI})}, \mathbf{q}^{*+(\mathrm{UAI})}\right)$ is the optimal solution of the following bilinear programming problem:

\section{Model 4}

$$
\begin{array}{r}
\max \left\{\left(\mathbf{p}^{+(\mathrm{UAI})}\right)^{\mathbf{T}} \mathbf{D}^{+(\mathrm{UAI})} \mathbf{q}^{+(\mathrm{UAI})}+\left(\mathbf{p}^{+(\mathrm{UAI})}\right)^{\mathrm{T}} \mathbf{E}^{+(\mathrm{UAI})} \mathbf{q}^{+(\mathrm{UAI})}-\mathrm{u}^{+(\mathrm{UAI})}-\mathrm{v}^{+(\mathrm{UAI})}\right\} \\
\text { s.t. }\left\{\begin{array}{c}
\mathbf{D}^{+(\mathrm{UAI})} \mathbf{q}^{+(\mathrm{UAI})} \leq \mathrm{u}^{+(\mathrm{UAI})} \mathrm{e}^{m} \\
\left(\mathbf{E}^{+(\mathrm{UAI})}\right)^{\mathrm{T}} \mathbf{p}^{+(\mathrm{UAI})} \leq \mathrm{v}^{+(\mathrm{UAI})} \mathrm{e}^{n} \\
\left(\mathbf{p}^{+(\mathrm{UAI})}\right)^{\mathrm{T}} \mathrm{e}^{m}=\mathbf{1} \\
\left(\mathbf{q}^{+(\mathrm{UAI})}\right)^{\mathrm{T}} \mathrm{e}^{n}=\mathbf{1} \\
\mathbf{p}^{+(\mathrm{UAI})} \geq \mathbf{0} \\
\mathbf{q}^{+(\mathrm{UAI})} \geq \mathbf{0} \\
\mathrm{u}^{+(\mathrm{UAI})}, \mathrm{v}^{+(\mathrm{UAI})} \text { unrestricted in sign }
\end{array}\right.
\end{array}
$$

The optimal solution of Eq. (8) $\left(\mathbf{p}^{*+(\text { UAI })}, \mathbf{q}^{*+(\text { UAI })}, \mathbf{u}^{+(\text {UAI })}, \mathbf{v}^{+(\text {UAI })}\right)$ can be obtained by using the Lingo software. Then, we get the upper upper bound $\mathbf{u}^{+(\mathrm{UAI})}$ and $\mathbf{v}^{+(\mathrm{UAI})}$ of the rough interval values of players I and II in the rough interval bimatrix game $\left(\mathbf{D}^{\mathbf{R}}, \mathbf{E}^{\mathbf{R}}\right)$ and the corresponding optimal strategies $\mathbf{p}^{*+(\mathbf{U A I})} \in \mathbf{P}$ and $\mathbf{q}^{*+(\mathbf{U A I})} \in \mathbf{Q}$, respectively.

Thus, we can get the rough interval values $\mathbf{u}^{R}=\left[\left(\mathbf{u}^{-(\mathrm{LAI})}, \mathbf{u}^{+(\mathrm{LAI})}\right):\left(\mathbf{u}^{-(\mathrm{UAI})}, \mathbf{u}^{+(\mathrm{UAI})}\right)\right]$ and $\mathbf{v}^{R}=$ $\left[\left(\mathbf{v}^{-(\mathbf{L A I})}, \mathbf{v}^{+(\mathbf{L A I})}\right):\left(\mathbf{v}^{-(\mathrm{UAI})}, \mathbf{v}^{+(\mathrm{UAI})}\right)\right]$ of players I and II in the rough interval bi-matrix game $\left(\mathbf{D}^{\mathbf{R}}, \mathbf{E}^{\mathbf{R}}\right)$ by solving the derived four bilinear programming problems Eq. (4), Eq. (5), Eq. (6) and Eq. (7).

Algorithm of the proposed method

Step 1. Identify the players, given by player I and player II.

Step 2. Identify the set of pure strategies for the player I and player II denoted by $\mathrm{S}_{1}=\left\{\gamma_{1}, \gamma_{2}, \ldots, \gamma_{m}\right\}$ and $\mathrm{S}_{2}=\left\{\rho_{1}, \rho_{2}, \ldots ., \rho_{n}\right\}$, respectively.

Step 3. Identify the set of constrained strategies for player I and player II denoted by P and Q, respectively

Step 4. Formulate and solve the bilinear programming models according to Eq. (5) to obtain the lower lower bound $\mathbf{u}^{-(\mathbf{L A I})}$ and $\mathbf{v}^{-(\mathbf{L A I})}$ of the rough interval values of player I and II and the corresponding optimal strategies $\mathbf{p}^{*-(\mathbf{L A I})}$ and $\mathbf{q}^{*-(\mathbf{L A I})}$.

Step 5. Construct and solve the bilinear programming models according to Eq. (6) to obtain the upper lower bound $\mathbf{u}^{+(\mathbf{L A I})}$ and $\mathbf{v}^{+(\mathbf{L A I})}$ of the rough interval values of player I and II and the corresponding optimal strategies $\mathbf{p}^{*+(\mathbf{L A I})}$ and $\mathbf{q}^{*+(\mathbf{L A I})}$.

Step 6. Formulate and solve the bilinear programming models according to Eq. (7) to obtain the lower upper bound $\mathbf{u}^{-(\mathbf{U A I})}$ and $\mathbf{v}^{-(\mathrm{UAI})}$ of the rough interval values of player I and II and the corresponding optimal 
strategies $\mathbf{p}^{*-(\mathbf{U A I})}$ and $\mathbf{q}^{*-(\mathrm{UAI})}$.

Step 7. Construct and solve the bilinear programming models according to Eq. (8) to obtain the upper upper bound $\mathbf{u}^{+(\mathrm{UAI})}$ and $\mathbf{v}^{+(\mathrm{UAI})}$ of the rough interval values of player I and II and the corresponding optimal strategies $\mathbf{p}^{*+(\mathbf{U A I})}$ and $\mathbf{q}^{*+(\mathrm{UAI})}$.

Step 8. We obtained the rough interval game value and the optimal strategies of the bi-matrix game $\left(\mathbf{D}^{\mathbf{R}}, \mathbf{E}^{\mathbf{R}}\right)$ with rough interval payoff.

Step 9. Stop.

\section{Approach 2: Trust measure of rough bi-matrix games}

It is clear that the rough intervals bilinear programming problems Eqs. (4) can be transformed to crisp bilinear programming problems using the trust measure of rough interval, which is very easy to solve by using the Lingo software as follows:

The vectors form of Eqs. (4) can be expressed as follows:

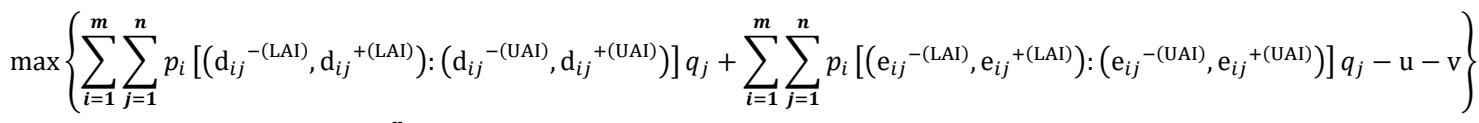

$$
\begin{aligned}
& \text { s.t. }\left\{\begin{array}{c}
\sum_{j=1}^{n}\left[\left(\mathrm{~d}_{i j}{ }^{-(\mathrm{LAIl})}, \mathrm{d}_{i j}{ }^{+(\mathrm{LAIl})}\right):\left(\mathrm{d}_{i j}{ }^{-(\mathrm{UAI})}, \mathrm{d}_{i j}{ }^{+(\mathrm{UAI})}\right)\right] q_{j} \leq \mathrm{u}(i=1,2, \ldots, m) \\
\sum_{i=1}^{m}\left[\left(\mathrm{e}_{i j}{ }^{-(\mathrm{LAIl})}, \mathrm{e}_{i j}{ }^{+(\mathrm{LAI})}\right):\left(\mathrm{e}_{i j}{ }^{-(\mathrm{UAI})}, \mathrm{e}_{i j}{ }^{+(\mathrm{UAI})}\right)\right] p_{i} \leq \mathrm{v}(j=1,2, \ldots, n) \\
\sum_{i=1}^{m} p_{i}=1 \\
\sum_{j=1}^{n} q_{j}=1 \\
p_{i} \geq 0(i=1,2, \ldots, m) \\
q_{j} \geq 0(j=1,2, \ldots, n) \\
\mathrm{u}, \mathrm{v} \text { unrestricted in sign }
\end{array}\right.
\end{aligned}
$$

By using Theorem 1, we can transform the rough intervals bilinear programming problems Eq. (9) to a crisp bilinear programming problem. Suppose that $\mathrm{d}^{R}{ }_{i j}=\left[\left(\mathrm{d}_{i j}{ }^{-(\mathrm{LAI})}, \mathrm{d}_{i j}{ }^{+(\mathrm{LAI})}\right):\left(\mathrm{d}_{i j}{ }^{-(\mathrm{UAI})}, \mathrm{d}_{i j}{ }^{+(\mathrm{UAI})}\right)\right]$ be a rough variable to the rough interval payoff matrix $\mathbf{D}^{\mathrm{R}}$ of player I. By using the confidence level $\alpha \in(0,1)$, the equivalent crisp constraints of Eqs. (9) can be written as follows:

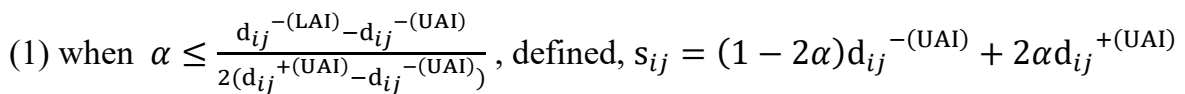

(2) when $\alpha \geq \frac{\mathrm{d}_{i j}{ }^{+(\mathrm{LAI})}+\mathrm{d}_{i j}{ }^{+(\mathrm{UAI})}-2 \mathrm{~d}_{i j}{ }^{-(\mathrm{UAI})}}{2\left(\mathrm{~d}_{i j}{ }^{+(\mathrm{UAI})}-\mathrm{d}_{i j}{ }^{-(\mathrm{UAI})}\right)}$, defined, $\mathrm{s}_{i j}=2(1-\alpha) \mathrm{d}_{i j}{ }^{-{ }^{-(\mathrm{UAI})}}+(2 \alpha-1) \mathrm{d}_{i j}{ }^{+(\mathrm{UAI})}$

$$
\text { when } \quad \frac{\mathrm{d}_{i j}{ }^{-(\mathrm{LAI})}-\mathrm{d}_{i j}{ }^{-(\mathrm{UAI})}}{2\left(\mathrm{~d}_{i j}{ }^{+(\mathrm{UAI})}-\mathrm{d}_{i j}{ }^{-(\mathrm{UAI})}\right)}<\alpha<\frac{\mathrm{d}_{i j}{ }^{+(\mathrm{LAI})}+\mathrm{d}_{i j}{ }^{+(\mathrm{UAI})}-2 \mathrm{~d}_{i j}{ }^{-(\mathrm{UAI})}}{2\left(\mathrm{~d}_{i j}{ }^{+(\mathrm{UAI})}-\mathrm{d}_{i j}{ }^{-(\mathrm{UAI})}\right)}
$$

defined, 
$\mathrm{s}_{i j}$

$=\frac{2 \alpha \mathrm{d}_{i j}{ }^{+(\mathrm{LAI})} \mathrm{d}_{i j}{ }^{+(\mathrm{UAI})}+(1-2 \alpha) \mathrm{d}_{i j}{ }^{-(\mathrm{LAI})} \mathrm{d}_{i j}{ }^{+(\mathrm{UAI})}+(1-2 \alpha) \mathrm{d}_{i j}{ }^{+(\mathrm{LAI})} \mathrm{d}_{i j}{ }^{-(\mathrm{UAI})}+2(\alpha-1) \mathrm{d}_{i j}{ }^{-{ }^{(\mathrm{LAI})} \mathrm{d}_{i j}{ }^{- \text {(UAI })}}}{\left(\mathrm{d}_{i j}{ }^{+(\mathrm{LAI})}-\mathrm{d}_{i j}{ }^{-(\mathrm{LAI})}\right)+\left(\mathrm{d}_{i j}{ }^{+(\mathrm{UAI})}-\mathrm{d}_{i j}{ }^{-(\mathrm{UAI})}\right)}$

Similarly, let $\mathrm{e}^{R}{ }_{i j}=\left[\left(\mathrm{e}_{i j}{ }^{-(\mathrm{LAI})}, \mathrm{e}_{i j}{ }^{+(\mathrm{LAI})}\right):\left(\mathrm{e}_{i j}{ }^{-(\mathrm{UAI})}, \mathrm{e}_{i j}{ }^{+(\mathrm{UAI})}\right)\right]$ be a rough variable to the rough interval payoff matrix $\mathbf{E}^{\mathrm{R}}$ of player II. By using the confidence level $\alpha \in(0,1)$, the equivalent crisp constraints of Eqs. (9) can be written as follows:

(1) when $\alpha \leq \frac{\mathrm{e}_{i j}{ }^{-(\mathrm{LAI})}-\mathrm{e}_{i j}{ }^{-(\mathrm{UAI})}}{2\left(\mathrm{e}_{i j}{ }^{+(\mathrm{UAI})}-\mathrm{e}_{i j}{ }^{-(\mathrm{UAI})}\right)}$, defined, $\mathrm{t}_{i j}=(1-2 \alpha) \mathrm{e}_{i j}{ }^{-(\mathrm{UAI})}+2 \alpha \mathrm{e}_{i j}{ }^{+(\mathrm{UAI})}$

(2) when $\alpha \geq \frac{\mathrm{e}_{i j}{ }^{+(\mathrm{LAI})}+\mathrm{e}_{i j}{ }^{+(\mathrm{UAI})}-2 \mathrm{e}_{i j}{ }^{-(\mathrm{UAI})}}{2\left(\mathrm{e}_{i j}{ }^{+(\mathrm{UAI})}-\mathrm{e}_{i j}{ }^{-(\mathrm{UAI})}\right)}$, defined, $\mathrm{t}_{i j}=2(1-\alpha) \mathrm{d}_{i j}{ }^{-(\mathrm{UAI})}+(2 \alpha-1) \mathrm{d}_{i j}{ }^{+(\mathrm{UAI})}$

$$
\text { when } \quad \frac{\mathrm{e}_{i j}{ }^{-(\mathrm{LAI})}-\mathrm{e}_{i j}{ }^{-(\mathrm{UAI})}}{2\left(\mathrm{e}_{i j}{ }^{+(\mathrm{UAI})}-\mathrm{e}_{i j}{ }^{-(\mathrm{UAI})}\right)}<\alpha<\frac{\mathrm{e}_{\mathrm{e}_{j}}{ }^{+(\mathrm{LAI})}+\mathrm{e}_{i j}{ }^{+(\mathrm{UAI})}-2 \mathrm{e}_{i j}{ }^{-(\mathrm{UAI})}}{2\left(\mathrm{e}_{i j}{ }^{+(\mathrm{UAI})}-\mathrm{e}_{i j}{ }^{-(\mathrm{UAI})}\right)} \quad, \quad \text { defined, }
$$

$\mathrm{t}_{i j}=\frac{2 \alpha \mathrm{e}_{i j}{ }^{+(\mathrm{LAI})} \mathrm{e}_{i j}{ }^{+(\mathrm{UAI})}+(1-2 \alpha) \mathrm{e}_{i j}{ }^{-(\mathrm{LAI})} \mathrm{e}_{i j}{ }^{+(\mathrm{UAI})}+(1-2 \alpha) \mathrm{e}_{i j}{ }^{+(\mathrm{LAI})} \mathrm{e}_{i j}{ }^{-(\mathrm{UAI})}+2(\alpha-1) \mathrm{e}_{i j}{ }^{-(\mathrm{LAI})} \mathrm{e}_{i j}{ }^{-(\mathrm{UAI})}}{\left(\mathrm{e}_{i j}{ }^{+(\mathrm{LAI})}-\mathrm{e}_{i j}{ }^{-(\mathrm{LAI})}\right)+\left(\mathrm{e}_{i j}{ }^{+(\mathrm{UAI})}-\mathrm{e}_{i j}{ }^{-(\mathrm{UAI})}\right)}$

Then for a specific value of confidence level $\alpha \in(0,1)$, then we can write the equivalent crisp bilinear programming problems of Eqs. (9) as follows:

$$
\begin{gathered}
\max \left\{\sum_{i=1}^{m} \sum_{j=1}^{n} p_{i} \mathrm{~s}_{i j} q_{j}+\sum_{i=1}^{m} \sum_{j=1}^{n} p_{i} \mathrm{t}_{i j} q_{j}-\mathrm{u}-\mathrm{v}\right\} \\
\text { s.t. }\left\{\begin{array}{c}
\sum_{j=1}^{n} \mathrm{~s}_{i j} q_{j} \leq \mathrm{u}(i=1,2, \ldots, m) \\
\sum_{i=1}^{m} \mathrm{t}_{i j} p_{i} \leq \mathrm{v}(j=1,2, \ldots, n) \\
\sum_{i=1}^{m} p_{i}=1 \\
\sum_{j=1}^{n} q_{j}=1 \\
p_{i} \geq 0(i=1,2, \ldots, m) \\
q_{j} \geq 0(j=1,2, \ldots, n) \\
\mathrm{u}, \mathrm{v} \text { unrestricted in sign }
\end{array}\right.
\end{gathered}
$$

Our proposed rough intervals bilinear programming problem Eqs. (9) change to a standard bilinear programming problem Eq. (10), relying on the value of confidence level $\alpha \in(0,1)$. The optimal strategies and the game value of player I and II can be obtained by solving Eqs. (10) using the Lingo software.

\section{Numerical Example}

In order to show the applicability of the proposed approach, we consider the problem of two tourism companies I and II taking a decision as to how to conquer a tourism target market. In this example, suppose that the tourism companies II and I will select the optimal strategies to maximize their own profit without cooperation. 
The company II has three strategies: remaining the status quo of the landscape $\left(\boldsymbol{\rho}_{\mathbf{1}}\right)$, enlarging the landscape $\left(\boldsymbol{\rho}_{2}\right)$ and reducing the landscape $\left(\boldsymbol{\rho}_{3}\right)$. And the tourism I has three strategies: remaining the status quo of the landscape $\left(\gamma_{1}\right)$, enlarging the landscape $\left(\gamma_{2}\right)$ and reducing the landscape $\left(\gamma_{3}\right)$. In this problem, the payoffs of outcomes cannot be realistically expressed by exact value representing the profit. So, the rough interval bimatrix game may be fittingly model the tourism planning management problem. Let us consider a rough interval bi-matrix game $\left(\mathbf{D}^{\mathbf{R}}, \mathbf{E}^{\mathbf{R}}\right)$, where the profits appeared for outcomes are given in rough interval matrix form as follows:

$$
\begin{aligned}
& \left(\mathrm{D}^{\mathrm{R}}, \mathrm{E}^{\mathrm{R}}\right) \\
& =\left(\begin{array}{ccc}
([(4,5):(3.3,5.6)],[(7.5,8):(7,9)]) & ([(2.5,3):(2,3.7)],[(6,7):(5.5,8)]) & ([(4,6):(3.5,7)],[(5,6):(4,7)]) \\
([(3,3.5):(2.5,4)],[(4,5):(3,6)]) & ([(5,7):(4.6,8)],[(8.5,9.5):(8,10)]) & ([(3,3.6):(2.4,4)],[(2.4,2.8):(2,3)]) \\
([(4,5.5):(3.5,6)],[(6,7):(5,8)]) & ([(3.6,3.9):(3.2,4)],[(5,7):(4,9)]) & ([(2,3):(1.5,3.8)],[(10,11):(9,12)])
\end{array}\right)
\end{aligned}
$$

Where the value $([(4,5):(3.3,5.6)],[(7.5,8):(7,9)])$ give the profit of the tourism company I varies within the variable ranges from 4 to 5 in most time and, in some special periods the profit range may vary from 3.3 to 5.6 and the profit of the tourism company II varies within the variable ranges from 7.5 to 8 in most cases and, in some special periods the profit range may vary from 7 to 9 if company I choose the strategy $\boldsymbol{\gamma}_{\mathbf{1}}$ and company II choose the strategy $\boldsymbol{\rho}_{\mathbf{1}}$. Other values in $\left(\mathbf{D}^{\mathbf{R}}, \mathbf{E}^{\mathbf{R}}\right)$ can be similarly described. We need to calculate the lower lower bound, the upper lower bound, the lower upper bound and the upper upper bound of the rough interval values of players I and II in the rough interval bi-matrix game $\left(\mathbf{D}^{\mathrm{R}}, \mathbf{E}^{\mathrm{R}}\right)$.

\subsection{Solution by proposed method.}

Using the method that given in Section 4 to obtain the rough interval equilibrium solution of the rough interval bi-matrix game $\left(\mathbf{D}^{\mathrm{R}}, \mathbf{E}^{\mathrm{R}}\right)$. From Eq. (5), the bilinear programming problem can be obtained as follows:

$$
\begin{aligned}
& \max \left\{\begin{array}{l}
11.5 \mathrm{p}_{1}{ }^{-(\mathrm{LAI})} \mathrm{q}_{1}{ }^{-(\mathrm{LAI})}+8.5 \mathrm{p}_{1}{ }^{-(\mathrm{LAI})} \mathrm{q}_{2}{ }^{-(\mathrm{LAI})}+9 \mathrm{p}_{1}{ }^{-(\mathrm{LAI})} \mathrm{q}_{3}{ }^{-(\mathrm{LAI})}+7 \mathrm{p}_{2}{ }^{-(\mathrm{LAI})} \mathrm{q}_{1}{ }^{-(\mathrm{LAI})}+13.5 \mathrm{p}_{2}{ }^{-(\mathrm{LAI})} \mathrm{q}_{2}{ }^{-(\mathrm{LAI})} \\
+5.4 \mathrm{p}_{2}{ }^{-(\mathrm{LAI})} \mathrm{q}_{3}{ }^{-(\mathrm{LAI})}+10 \mathrm{p}_{3}{ }^{-(\mathrm{LAI})} \mathrm{q}_{1}{ }^{-(\mathrm{LAI})}+8.6 \mathrm{p}_{3}{ }^{-(\mathrm{LAI})} \mathrm{q}_{2}{ }^{-(\mathrm{LAI})}+12 \mathrm{p}_{3}{ }^{-(\mathrm{LAI})} \mathrm{q}_{3}{ }^{-(\mathrm{LAI})}-\mathrm{u}^{-(\mathrm{LAI})}-\mathrm{v}^{-(\mathrm{LAI})}
\end{array}\right\}
\end{aligned}
$$

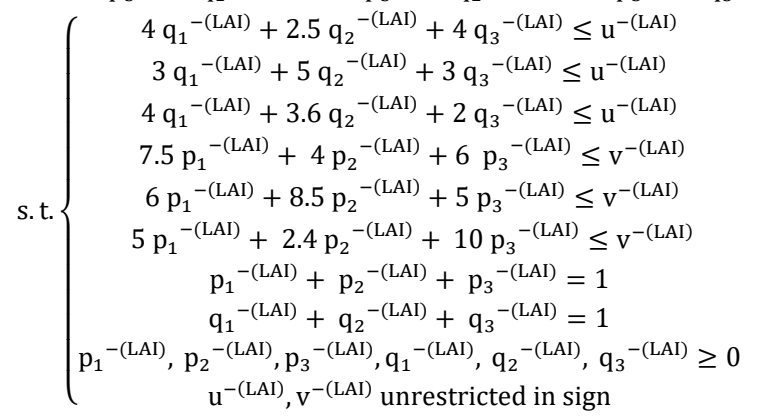

The optimal solution $\left(\mathbf{p}^{*-(\mathrm{LAI})}, \mathbf{q}^{*-(\mathrm{LAI})}, \mathrm{u}^{-(\mathrm{LAI})}, \mathrm{v}^{-(\mathrm{LAI})}\right)$ of Eq. (11) can be obtained by using the Lingo software, where $\mathbf{p}^{*-(\mathrm{LAI})}=(0.425,0.22,0.354)^{\mathrm{T}}, \mathbf{q}^{*-(\mathrm{LAI})}=(0.557,0.286,0.157)^{\mathrm{T}}, \mathrm{u}^{-(\mathrm{LAI})}=3.571$ and $\mathrm{v}^{-(\mathrm{LAI})}=6.197$. Thus, the lower lower bound value of the tourism companies I and II are $\mathrm{u}^{-(\mathrm{LAI})}=3.571$ and $\mathrm{v}^{-(\mathrm{LAI})}=6.197$, respectively.

Likewise, according to Eq. (6), the bilinear programming problem can be expressed as follows: 


$$
\begin{aligned}
& \max \left\{\begin{array}{c}
13 \mathrm{p}_{1}{ }^{+(\mathrm{LAI})} \mathrm{q}_{1}{ }^{+(\mathrm{LAI})}+10 \mathrm{p}_{1}{ }^{+(\mathrm{LAI})} \mathrm{q}_{2}{ }^{+(\mathrm{LAI})}+12 \mathrm{p}_{1}{ }^{+(\mathrm{LAI})} \mathrm{q}_{3}{ }^{+(\mathrm{LAI})}+8.5 \mathrm{p}_{2}{ }^{+(\mathrm{LAI})} \mathrm{q}_{1}{ }^{+(\mathrm{LAI})}+16.5 \mathrm{p}_{2}{ }^{+(\mathrm{LAI})} \mathrm{q}_{2}{ }^{+(\mathrm{LAI})} \\
+6.4 \mathrm{p}_{2}{ }^{+(\mathrm{LAI})} \mathrm{q}_{3}{ }^{+(\mathrm{LAI})}+12.5 \mathrm{p}_{3}{ }^{+(\mathrm{LAI})} \mathrm{q}_{1}{ }^{+(\mathrm{LAI})}+10.9 \mathrm{p}_{3}{ }^{+(\mathrm{LAI})} \mathrm{q}_{2}{ }^{+(\mathrm{LAI})}+14 \mathrm{p}_{3}{ }^{+(\mathrm{LAI})} \mathrm{q}_{3}{ }^{+(\mathrm{LAI})}-\mathrm{u}^{+(\mathrm{LAI})}-\mathrm{v}^{+(\mathrm{LAI})}
\end{array}\right\} \\
& \text { s.t. }\left\{\begin{array}{c}
5 \mathrm{q}_{1}{ }^{+(\mathrm{LAI})}+3 \mathrm{q}_{2}{ }^{+(\mathrm{LAI})}+6 \mathrm{q}_{3}{ }^{+(\mathrm{LAI})} \leq \mathrm{u}^{+(\mathrm{LAI})} \\
3.5 \mathrm{q}_{1}{ }^{+(\mathrm{LAI})}+7 \mathrm{q}_{2}{ }^{+(\mathrm{LAI})}+3.6 \mathrm{q}_{3}{ }^{+(\mathrm{LAI})} \leq \mathrm{u}^{+(\mathrm{LAI})} \\
5.5 \mathrm{q}_{1}{ }^{+(\mathrm{LAI})}+3.9 \mathrm{q}_{2}{ }^{+(\mathrm{LAI})}+3 \mathrm{q}_{3}{ }^{+(\mathrm{LAI})} \leq \mathrm{u}^{+(\mathrm{LAI})} \\
8 \mathrm{p}_{1}{ }^{+(\mathrm{LAI})}+5 \mathrm{p}_{2}{ }^{+(\mathrm{LAI})}+7 \mathrm{p}_{3}{ }^{+(\mathrm{LAI})} \leq \mathrm{v}^{+(\mathrm{LAI})} \\
7 \mathrm{p}_{1}{ }^{+(\mathrm{LAI})}+9.5 \mathrm{p}_{2}{ }^{+(\mathrm{LAI})}+7 \mathrm{p}_{3}{ }^{+(\mathrm{LAI})} \leq \mathrm{v}^{+(\mathrm{LAI})} \\
6 \mathrm{p}_{1}{ }^{+(\mathrm{LAI})}+2.8 \mathrm{p}_{2}{ }^{+(\mathrm{LAI})}+11 \mathrm{p}_{3}{ }^{+(\mathrm{LAI})} \leq \mathrm{v}^{+(\mathrm{LAI})} \\
\mathrm{p}_{1}{ }^{+(\mathrm{LAI})}+\mathrm{p}_{2}{ }^{+(\mathrm{LAI})}+\mathrm{p}_{3}{ }^{+(\mathrm{LAI})}=1 \\
\mathrm{q}_{1}{ }^{+(\mathrm{LAI})}+\mathrm{q}_{2}{ }^{+(\mathrm{LAI})}+\mathrm{q}_{3}{ }^{+(\mathrm{LAI})}=1 \\
\mathrm{p}_{1}{ }^{+(\mathrm{LAI})}, \mathrm{p}_{2}{ }^{+(\mathrm{LAI})}, \mathrm{p}_{3}{ }^{+(\mathrm{LAI})}, \mathrm{q}_{1}{ }^{+(\mathrm{LAI})}, \mathrm{q}_{2}{ }^{+(\mathrm{LAI})}, \mathrm{q}_{3}{ }^{+(\mathrm{LAI})} \geq 0 \\
\mathrm{u}^{+(\mathrm{LAI})}, \mathrm{v}^{+(\mathrm{LAI})} \text { unrestricted in sign }
\end{array}\right.
\end{aligned}
$$

The optimal solution $\left(\mathbf{p}^{*+(\mathrm{LAI})}, \mathbf{q}^{*+(\mathrm{LAI})}, \mathrm{u}^{+(\mathrm{LAI})}, \mathrm{v}^{+(\mathrm{LAI})}\right)$ of Eq. (12) can be obtained by using the Lingo software, where $\mathbf{p}^{*+(\mathrm{LAI})}=(0.542,0.12,0.337)^{\mathrm{T}}, \mathbf{q}^{*+(\mathrm{LAI})}=(0.521,0.302,0.177)^{\mathrm{T}}, \mathrm{u}^{+(\mathrm{LAI})}=4.574$ and $\mathrm{v}^{+(\mathrm{LAI})}=7.301$. Thus, the upper lower bound value of the tourism companies I and II are $\mathrm{u}^{+(\mathrm{LAI})}=4.574$ and $\mathrm{V}^{+(\mathrm{LAI})}=7.301$, respectively.

Similarly, according to Eq. (7), the bilinear programming problem can be expressed as follows:

$$
\begin{aligned}
& \max \left\{\begin{array}{c}
10.3 \mathrm{p}_{1}{ }^{-(\mathrm{UAI})} \mathrm{q}_{1}{ }^{-(\mathrm{UAI})}+7.5 \mathrm{p}_{1}{ }^{-(\mathrm{UAI})} \mathrm{q}_{2}{ }^{-(\mathrm{UAI})}+7.5 \mathrm{p}_{1}{ }^{-(\mathrm{UAI})} \mathrm{q}_{3}{ }^{-(\mathrm{UAI})}+5.5 \mathrm{p}_{2}{ }^{-(\mathrm{UAI})} \mathrm{q}_{1}{ }^{-(\mathrm{UAI})}+12.6 \mathrm{p}_{2}{ }^{-(\mathrm{UAI})} \mathrm{q}_{2}{ }^{-(\mathrm{UAI})} \\
+4 . .4 \mathrm{p}_{2}{ }^{-(\mathrm{UAI})} \mathrm{q}_{3}{ }^{-(\mathrm{UAI})}+8.5 \mathrm{p}_{3}{ }^{-(\mathrm{UAI})} \mathrm{q}_{1}{ }^{-(\mathrm{UAI})}+7.2 \mathrm{p}_{3}{ }^{-(\mathrm{UAI})} \mathrm{q}_{2}{ }^{-(\mathrm{UAI})}+10.5 \mathrm{p}_{3}{ }^{-(\mathrm{UAI})} \mathrm{q}_{3}{ }^{-(\mathrm{UAI})}-\mathrm{u}^{-(\mathrm{UAI})}-\mathrm{v}^{-(\mathrm{UAI})}
\end{array}\right\} \\
& \text { s.t. }\left\{\begin{array}{c}
3.3 \mathrm{q}_{1}{ }^{-(\mathrm{UAI})}+2 \mathrm{q}_{2}{ }^{-(\mathrm{UAI})}+3.5 \mathrm{q}_{3}^{-(\mathrm{UAI})} \leq \mathrm{u}^{-(\mathrm{UAI})} \\
2.5 \mathrm{q}_{1}{ }^{-(\mathrm{UAI})}+4.6 \mathrm{q}_{2}{ }^{-(\mathrm{UAI})}+2.4 \mathrm{q}_{3}{ }^{-(\mathrm{UAI})} \leq \mathrm{u}^{-(\mathrm{UAI})} \\
3.5 \mathrm{q}_{1}{ }^{-(\mathrm{UAI})}+3.2 \mathrm{q}_{2}{ }^{-(\mathrm{UAI})}+1.5 \mathrm{q}_{3}{ }^{-(\mathrm{UAI})} \leq \mathrm{u}^{-(\mathrm{UAI})} \\
7 \mathrm{p}_{1}{ }^{-(\mathrm{UAI})}+3 \mathrm{p}_{2}{ }^{-(\mathrm{UAI})}+5 \mathrm{p}_{3}{ }^{-(\mathrm{UAI})} \leq \mathrm{v}^{-(\mathrm{UAI})} \\
5.5 \mathrm{p}_{1}{ }^{-(\mathrm{UAI})}+8 \mathrm{p}_{2}{ }^{-(\mathrm{UAI})}+4 \mathrm{p}_{3}{ }^{-(\mathrm{UAI})} \leq \mathrm{v}^{-(\mathrm{UAI})} \\
4 \mathrm{p}_{1}{ }^{-(\mathrm{UAI})}+2 \mathrm{p}_{2}{ }^{-(\mathrm{UAI})}+9 \mathrm{p}_{3}{ }^{-(\mathrm{UAI})} \leq \mathrm{v}^{-(\mathrm{UAI})} \\
\mathrm{p}_{1}^{-(\mathrm{UAI})}+\mathrm{p}_{2}{ }^{-(\mathrm{UAI})}+\mathrm{p}_{3}{ }^{-(\mathrm{UAI})}=1 \\
\mathrm{q}_{1}^{-(\mathrm{UAI})}+\mathrm{q}_{2}{ }^{-(\mathrm{UAI})}+\mathrm{q}_{3}{ }^{-(\mathrm{UAI})}=1 \\
\mathrm{p}_{1}{ }^{-(\mathrm{UAI})}, \mathrm{p}_{2}{ }^{-(\mathrm{UAI})}, \mathrm{p}_{3}{ }^{-(\mathrm{UAI})}, \mathrm{q}_{1}{ }^{-(\mathrm{UAI})}, \mathrm{q}_{2}{ }^{-(\mathrm{UAI})}, \mathrm{q}_{3}{ }^{-(\mathrm{UAI})} \geq 0 \\
\mathrm{u}^{-(\mathrm{UAI})}, \mathrm{v}^{-(\mathrm{UAI})} \text { unrestricted in sign }
\end{array}\right.
\end{aligned}
$$

The optimal solution $\left(\mathbf{p}^{*-(\mathrm{UAI})}, \mathbf{q}^{*-(\mathrm{UAI})}, \mathrm{u}^{-(\mathrm{UAI})}, \mathrm{v}^{-(\mathrm{UAI})}\right)$ of Eq. (13) can be obtained by using the Lingo software, where $\mathbf{p}^{*-(\mathrm{UAI})}=(0.427,0.202,0.371)^{\mathrm{T}}, \mathbf{q}^{*-(\mathrm{UAI})}=(0.54,0.253,0.206)^{\mathrm{T}}, \mathrm{u}^{-(\mathrm{UAI})}=3.012$ and $\mathrm{v}^{-(\mathrm{UAI})}=5.449$. Thus, the lower upper bound value of the tourism companies I and II are $\mathrm{u}^{-(\mathrm{UAI})}=3.012$ and $\mathrm{v}^{-(\mathrm{UAI})}=5.449$, respectively.

Likewise, according to Eq. (8), the bilinear programming problem can be expressed as follows: 


$$
\begin{aligned}
& \max \left\{\begin{array}{c}
\left.14.6 \mathrm{p}_{1}{ }^{+(\mathrm{UAI})} \mathrm{q}_{1}{ }^{+(\mathrm{UAI})}+11.7 \mathrm{p}_{1}^{+(\mathrm{UAI})} \mathrm{q}_{2}{ }^{+(\mathrm{UAI})}+14 \mathrm{p}_{1}{ }^{+(\mathrm{UAI})} \mathrm{q}_{3}{ }^{+(\mathrm{UAI})}+10 \mathrm{p}_{2}{ }^{+(\mathrm{UAI})} \mathrm{q}_{1}{ }^{+(\mathrm{UAI})}+18 \mathrm{p}_{2}{ }^{+(\mathrm{UAI})} \mathrm{q}_{2}{ }^{+(\mathrm{UAI})}\right) \\
+7 \mathrm{p}_{2}{ }^{+(\mathrm{UAI})} \mathrm{q}_{3}{ }^{+(\mathrm{UAI})}+14 \mathrm{p}_{3}{ }^{+(\mathrm{UAI})} \mathrm{q}_{1}{ }^{+(\mathrm{UAI})}+13 \mathrm{p}_{3}{ }^{+(\mathrm{UAI})} \mathrm{q}_{2}{ }^{+(\mathrm{UAI})}+15.8 \mathrm{p}_{3}{ }^{+(\mathrm{UAI})} \mathrm{q}_{3}{ }^{+(\mathrm{UAI})}-\mathrm{u}^{+(\mathrm{UAI})}-\mathrm{v}^{+(\mathrm{UAI})}
\end{array}\right\}
\end{aligned}
$$

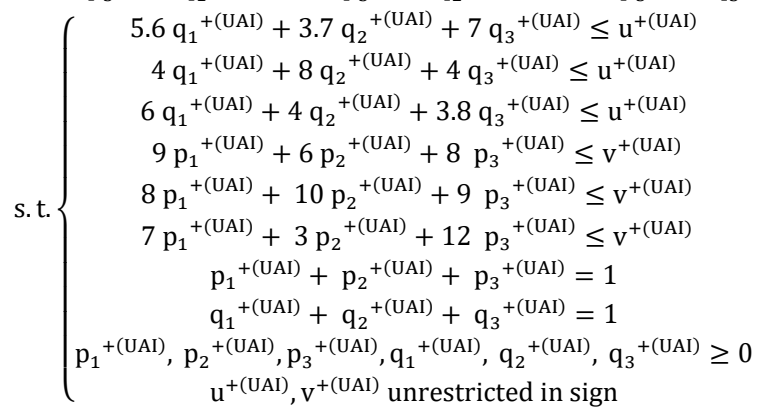

The optimal solution $\left(\mathbf{p}^{*+(\mathrm{UAI})}, \mathbf{q}^{*+(\mathrm{UAI})}, \mathrm{u}^{+(\mathrm{UAI})}, \mathrm{v}^{+(\mathrm{UAI})}\right)$ of Eq. (14) can be obtained by using the Lingo software, where $\mathbf{p}^{*+(\mathrm{UAI})}=(0.594,0.063,0.344)^{\mathrm{T}}, \mathbf{q}^{*+(\mathrm{UAI})}=(0.601,0.296,0.103)^{\mathrm{T}}, \mathrm{u}^{+(\mathrm{UAI})}=5.182$ and $\mathrm{v}^{+(\mathrm{UAI})}=8.469$. Thus, the upper upper bound value of the tourism companies I and II are $\mathrm{u}^{+(\mathrm{UAI})}=5.182$ and $\mathrm{v}^{+(\mathrm{UAI})}=8.469$, respectively. Then, the rough interval values of tourism companies I and II in the rough interval bimatrix game $\left(\mathbf{D}^{\mathbf{R}}, \mathbf{E}^{\mathbf{R}}\right) \quad$ are $\left[\left(\mathrm{u}^{-(\mathrm{LAI})}, \mathrm{u}^{+(\mathrm{LAI})}\right):\left(\mathrm{u}^{-(\mathrm{UAI})}, \mathrm{u}^{+(\mathrm{UAI})}\right)\right]=[(3.571,4.574):(3.012,5.182)] \quad$ and $\left[\left(\mathrm{v}^{-(\mathrm{LAI})}, \mathrm{v}^{+(\mathrm{LAI})}\right):\left(\mathrm{v}^{-(\mathrm{UAI})}, \mathrm{v}^{+(\mathrm{UAI})}\right)\right]=[(6.197,7.301):(5.449,8.469)]$, respectively.

\subsection{Solution by expected value operator.}

Using the expected value of rough interval that given in Remark 1 when $\mu=0.5$ to example 7 we obtain the following crisp bilinear programming problems as follows:

$$
\begin{array}{r}
\max \left\{\begin{array}{c}
12.35 \mathrm{p}_{1} \mathrm{q}_{1}+9.425 \mathrm{p}_{1} \mathrm{q}_{2}+10.625 \mathrm{p}_{1} \mathrm{q}_{3}+7.75 \mathrm{p}_{2} \mathrm{q}_{1}+15.15 \mathrm{p}_{2} \mathrm{q}_{2} \\
+5.8 \mathrm{p}_{2} \mathrm{q}_{3}+11.25 \mathrm{p}_{3} \mathrm{q}_{1}+9.925 \mathrm{p}_{3} \mathrm{q}_{2}+13.075 \mathrm{p}_{3} \mathrm{q}_{3}-\mathrm{u}-\mathrm{v}
\end{array}\right\} \\
\text { s.t. }\left\{\begin{array}{c}
4.475 \mathrm{q}_{1}+2.8 \mathrm{q}_{2}+5.125 \mathrm{q}_{3} \leq \mathrm{u} \\
3.25 \mathrm{q}_{1}+6.15 \mathrm{q}_{2}+3.25 \mathrm{q}_{3} \leq \mathrm{u} \\
4.75 \mathrm{q}_{1}+3.675 \mathrm{q}_{2}+2.575 \mathrm{q}_{3} \leq \mathrm{u} \\
7.875 \mathrm{p}_{1}+4.5 \mathrm{p}_{2}+6.5 \mathrm{p}_{3} \leq \mathrm{v} \\
6.625 \mathrm{p}_{1}+9 \mathrm{p}_{2}+6.25 \mathrm{p}_{3} \leq \mathrm{v} \\
5.5 \mathrm{p}_{1}+2.55 \mathrm{p}_{2}+10.5 \mathrm{p}_{3} \leq \mathrm{v} \\
\mathrm{p}_{1}+\mathrm{p}_{2}+\mathrm{p}_{3}=1 \\
\mathrm{q}_{1}+\mathrm{q}_{2}+\mathrm{q}_{3}=1 \\
\mathrm{p}_{1}, \mathrm{p}_{2}, \mathrm{p}_{3} \mathrm{q}_{1}, \mathrm{q}_{2}, \mathrm{q}_{3} \geq 0 \\
\mathrm{u}, \mathrm{v} \text { unrestricted in sign }
\end{array}\right.
\end{array}
$$

The optimal solution $\left(\mathbf{p}^{*}, \mathbf{q}^{*}, \mathrm{u}, \mathrm{v}\right)$ of Eq. (15) can be obtained by using the Lingo software, where $\mathbf{p}^{*}=$ $(0.483,0.154,0.363)^{\mathrm{T}}, \mathbf{q}^{*}=(0.55,0.291,0.159)^{\mathrm{T}}, \mathrm{u}=4.094$ and $\mathrm{v}=6.858$. Thus, the value of the tourism companies I and II are $\mathrm{u}=4.094$ and $\mathrm{v}=6.858$, respectively.

\subsection{Solution by trust measure operator.}

Using the method that given in Section 6 to obtain the equilibrium solution of the rough interval bi-matrix 
game. From Eqs. (10), then the equivalent crisp bilinear programming problems with a particular choice of confidence level $\alpha=0.8$ given as follow:

$$
\begin{array}{r}
\max \left\{\begin{array}{c}
13.1 \mathrm{p}_{1} \mathrm{q}_{1}+10.02 \mathrm{p}_{1} \mathrm{q}_{2}+11.8 \mathrm{p}_{1} \mathrm{q}_{3}+8.43 \mathrm{p}_{2} \mathrm{q}_{1}+16.27 \mathrm{p}_{2} \mathrm{q}_{2} \\
+6.27 \mathrm{p}_{2} \mathrm{q}_{3}+12.26 \mathrm{p}_{3} \mathrm{q}_{1}+10.84 \mathrm{p}_{3} \mathrm{q}_{2}+13.91 \mathrm{p}_{3} \mathrm{q}_{3}-\mathrm{u}-\mathrm{v}
\end{array}\right\} \\
\text { s.t. }\left\{\begin{array}{c}
4.9 \mathrm{q}_{1}+3.02 \mathrm{q}_{2}+5.85 \mathrm{q}_{3} \leq \mathrm{u} \\
3.48 \mathrm{q}_{1}+6.87 \mathrm{q}_{2}+3.53 \mathrm{q}_{3} \leq \mathrm{u} \\
5.31 \mathrm{q}_{1}+3.84 \mathrm{q}_{2}+2.96 \mathrm{q}_{3} \leq \mathrm{u} \\
8.2 \mathrm{p}_{1}+4.95 \mathrm{p}_{2}+6.95 \mathrm{p}_{3} \leq \mathrm{v} \\
7 \mathrm{p}_{1}+9.4 \mathrm{p}_{2}+7 \mathrm{p}_{3} \leq \mathrm{v} \\
5.95 \mathrm{p}_{1}+2.74 \mathrm{p}_{2}+10.95 \mathrm{p}_{3} \leq \mathrm{v} \\
\mathrm{p}_{1}+\mathrm{p}_{2}+\mathrm{p}_{3}=1 \\
\mathrm{q}_{1}+\mathrm{q}_{2}+\mathrm{q}_{3}=1 \\
\mathrm{p}_{1}, \mathrm{p}_{2}, \mathrm{p}_{3} \mathrm{q}_{1}, \mathrm{q}_{2}, \mathrm{q}_{3} \geq 0 \\
\mathrm{u}, \mathrm{v} \text { unrestricted in sign }
\end{array}\right.
\end{array}
$$

The optimal solution $\left(\mathbf{p}^{*}, \mathbf{q}^{*}, \mathrm{u}, \mathrm{v}\right)$ of Eq. (16) can be obtained by using the Lingo software, where $\mathbf{p}^{*}=$ $(0.508,0.133,0.359)^{\mathrm{T}}, \mathbf{q}^{*}=(0.542,0.297,0.161)^{\mathrm{T}}, \mathrm{u}=4.495$ and $\mathrm{v}=7.319$. Thus, the value of the tourism companies I and II are $\mathrm{u}=4.495$ and $\mathrm{v}=7.319$, respectively.

\subsection{Discussion}

Many studies have been done to study the uncertainty in game theory, such as, [33], the authors discussed the equilibrium of fuzzy interval matrix game. [15] have proposed a bi-rough programming technique for solving the bi-matrix games under bi-rough environment. Reference [16] discussed a fuzzy based genetic algorithm for solving the bi-matrix entropy goal game. [17] established a fuzzy based genetic algorithm to solve the multiobjective bi-matrix entropy game. [31] discussed the solution of matrix games with payoff of the rough interval numbers using trust measure of rough number and obtained exact values of the game value for both players which are not desirable. [30] analyzed the bi-matrix game in rough interval environment and used the rough expected value operator to find the expected equilibrium strategies.

In this article, we solve a bi-matrix game using three different methods, namely solution using bilinear programming technique, which is our proposed technique, another is the expected value of rough interval and the last one is the trust measure of the rough number. In all the three methods we obtained the game value and the equilibrium strategies of the problem under study. However, in our proposed technique, it is ensured that any bi-matrix game with rough interval payoffs has rough interval number type game value. For different value of confidence level $\alpha$, we have obtained the players optimal strategies of the rough interval bi-matrix game $\left(\mathbf{D}^{\mathbf{R}}, \mathbf{E}^{\mathbf{R}}\right)$ as shown in Table 1.

From Table 2 it is obvious that the game value for player I that achieved using the expected value operator when $\mu=0.5$ and the trust measure with different confidence level $\alpha$ each of these solutions belong to the game value solution space that obtained using our proposed method that given in section 7.1. This will make the decision makers feel relax to make the decision in a range. Another advantage of the proposed technique that it is easily understandable by anyone who has the basic idea about rough intervals and intervals number properties, but in trust measure technique one should know the optimistic value, the approximation space and the pessimistic value etc. 
Table. 1. The optimal strategies of players I and II of the rough interval bi-matrix game.

\begin{tabular}{|c|c|c|c|c|c|c|c|}
\hline \multicolumn{8}{|c|}{ Optimal solutions by proposed method } \\
\hline \multicolumn{4}{|c|}{ Player I } & \multicolumn{4}{|c|}{ Player II } \\
\hline $\mathbf{p}^{-(\mathbf{L A I})}$ & $\mathbf{p}^{+(\mathbf{L A I})}$ & $\mathbf{p}^{-(\mathrm{UAI})}$ & $\mathbf{p}^{+(\mathrm{UAI})}$ & $\mathbf{q}^{-(\mathbf{L A I})}$ & $\mathbf{q}^{+(\text {LAI })}$ & $\mathbf{q}^{-(\mathrm{UAI})}$ & $\mathbf{q}^{+(\mathrm{UAI})}$ \\
\hline$(0.425,0.22,0.354)$ & $\left(\begin{array}{c}0.542, \\
0.12, \\
0.337\end{array}\right)$ & $\left(\begin{array}{l}0.427, \\
0.202, \\
0.371\end{array}\right)$ & $\left(\begin{array}{l}0.594, \\
0.063, \\
0.344\end{array}\right)$ & $\left(\begin{array}{l}0.557, \\
0.286, \\
0.157\end{array}\right)$ & $\left(\begin{array}{l}0.521, \\
0.302, \\
0.177\end{array}\right)$ & $\left(\begin{array}{c}0.54, \\
0.253, \\
0.206\end{array}\right)$ & $\left(\begin{array}{l}0.601, \\
0.296, \\
0.103\end{array}\right)$ \\
\hline \multicolumn{8}{|c|}{ Optimal solutions by expected value operator method } \\
\hline \multicolumn{4}{|c|}{ Player I } & \multicolumn{4}{|c|}{ Player II } \\
\hline \multicolumn{4}{|c|}{$(0.483,0.154,0.363)$} & \multicolumn{4}{|c|}{$(0.55,0.291,0.159)$} \\
\hline \multicolumn{8}{|c|}{ Optimal solutions by trust measure } \\
\hline \multicolumn{4}{|c|}{ Player I } & \multicolumn{4}{|c|}{ Player II } \\
\hline Confidence level $\alpha$ & \multicolumn{3}{|c|}{$\mathrm{p}^{T}$} & \multicolumn{4}{|c|}{$\mathrm{q}^{T}$} \\
\hline 0.1 & \multicolumn{3}{|c|}{$(0.447,0.177,0.375)$} & \multicolumn{4}{|c|}{$(0.527,0.278,0.195)$} \\
\hline 0.2 & \multicolumn{3}{|c|}{$(0.442,0.198,0.359)$} & \multicolumn{4}{|c|}{$(0.563,0.281,0.156)$} \\
\hline 0.4 & \multicolumn{3}{|c|}{$(0469,0.173,0.358)$} & \multicolumn{4}{|c|}{$(0.549,0.288,0.163)$} \\
\hline 0.6 & \multicolumn{3}{|c|}{$(0.499,0.148,0.353)$} & \multicolumn{4}{|c|}{$(0.544,0.293,0.164)$} \\
\hline 0.8 & \multicolumn{3}{|c|}{$(0.508,0.133,0.359)$} & \multicolumn{4}{|c|}{$(0.542,0.297,0.161)$} \\
\hline 0.99 & \multicolumn{3}{|c|}{$(0.589,0.654,0.346)$} & \multicolumn{4}{|c|}{$(0.600,0.295,0.104)$} \\
\hline
\end{tabular}

Table. 2. The game values of the rough interval bi-matrix game.

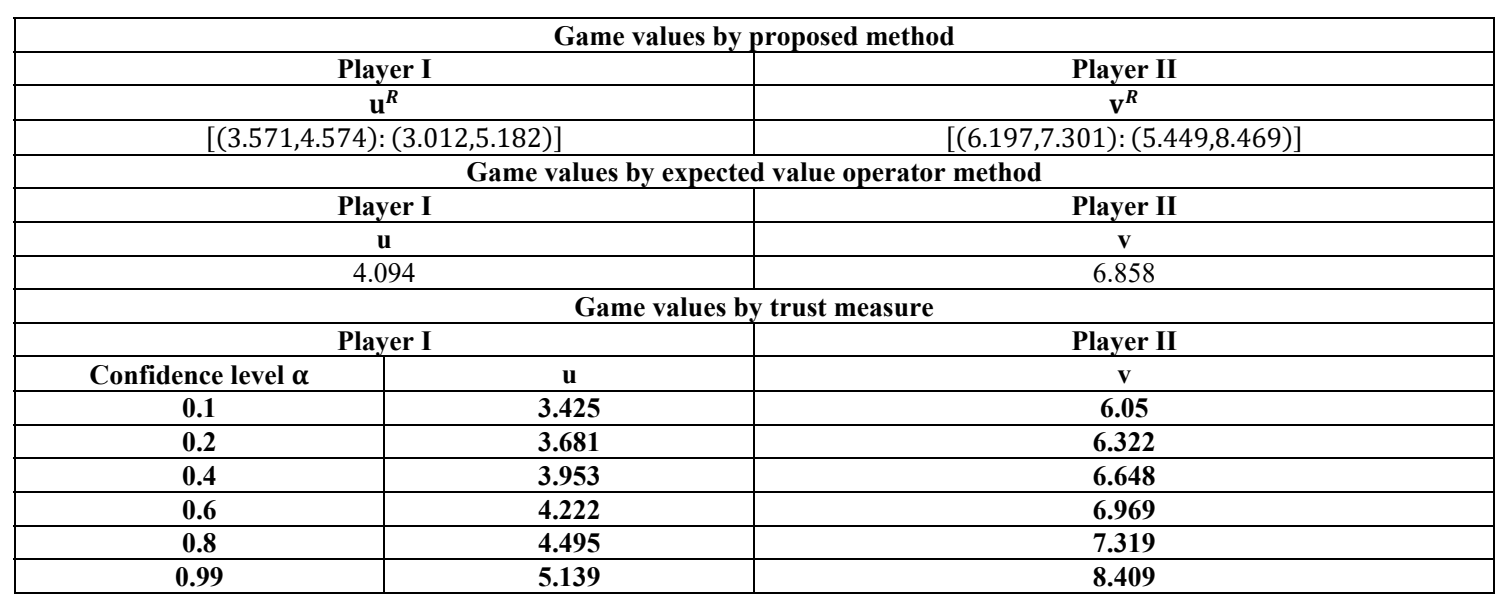

\section{Conclusion}

This paper uses rough sets to measure the uncertainties in bi-matrix games. We developed a novel and simple bilinear programming technique for solving bi-matrix game with rough interval payoffs, the proposed technique can ensure that any rough bi-matrix game has the rough interval-type value. Particularly, this rough interval-type value can be explicitly obtained by solving the deduced four bilinear programming problems upper lower problem, lower lower problem, lower upper problem and upper upper problem. We also obtained the optimal solutions of the proposed model by using the expected value operator and the trust measure with a 
confidence level of rough intervals. On the other hand, the bilinear programming technique proposed in this article can explicitly obtain the corresponding optimal strategies and the rough type game value for the two players in any rough bi-matrix game.

Although the effectiveness of the proposed technique is discussed with a numerical experiment of tourism planning management model as an application, it is predicted that the proposed technique and models can be applied to solving countless antagonistic decision-making problems in the same fields such as economics, search, location-quantity, management, finance and biology.

In the future study, the results of this article can be applied to matrix game with bi-rough parameters. Moreover, the proposed technique can be extended in other rough game such as rough zero-sum matrix game and rough coalition game.

\section{Acknowledgements}

The authors would like to thank the editor and the anonymous reviewers for their helpful comments for revising the article.

\section{Funding}

This work was partly supported by the National Key Research an Development Program of China (No.2017YFB0305601), the National Key Research an Development Program of China (No. 2017YFB0701700).

\section{Conflict of Interests}

No conflict of interests declared by author.

\section{References}

[1] J. Von Neumann and D. Morgenstern, “The theory of games in economic bahavior,” J. Wiley, Ne w York, 1944.

[2]I. C. Hung, K. H. Hsia, and L. W. Chen, "Fuzzy differential game of guarding a movable territory," Inf. Sci., vol. 91, pp. 113-131, 1996.

[3] J. C. Harsanyi, "Games with incomplete information played by "BayesianÝ players. I. The basic model," Manage. Sci., vol. 14, pp. 159-182, 1967.

[4] J. Xu, "Zero sum two-person game with grey number payoff matrix in linear programming," J. Grey Syst., vol. 10 , no. 3 , pp. 225-233, 1998.

[5] A. K. Dhingra and S. S. Rao, "A cooperative fuzzy game theoretic approach to multiple objective design optimization,” Eur. J. Oper. Res., vol. 83, pp. 547-567, 1995.

[6] S. Takahashi, "The number of pure Nash equilibria in a random game with nondecreasing best responses," Games Econ. Behav., vol. 63, no. 1, pp. 328-340, 2008.

[7]R. Espin, E. Fernandez, G. Mazcorro, and M. Ines, “A fuzzy approach to cooperative n -person games,” Eur. J. Oper. Res., vol. 176, no. 3, pp. 1735-1751, 2007.

[8] Z. Pawlak, “Rough sets,” Int. J. Comput. Inf. Sci., vol. 11, no. 5, pp. 341-356, 1982.

[9] Z. Pawlak and A. Skowron, "Rudiment of rough sets," Inf. Sci. (Ny)., vol. 177, no. 1, pp. 3-27, 2007.

[10]J. H. Nasiri and M. Mashinchi, "Rough set and data analysis in decision tables," J. Uncertain Syst., vol. 3, no. 3, pp. 232-240, 2009.

[11]Y. Weigou, L. Mingyu, and L. Zhi, "Variable precision rough set based decision tree classifier," J. Intell.

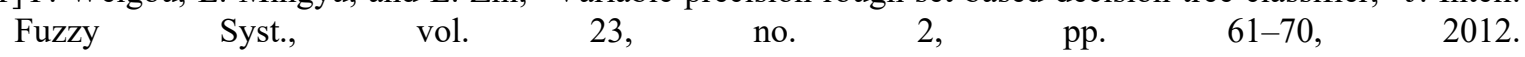


[12]M. Arabani and M. A. L. Nashaei, "Application of rough set theory as a new approach to simplify dams location," Sci. Iran., vol. 13, no. 2, pp. 152-158, 2006.

[13]M. Rebolledo, "Rough intervals enhancing intervals for qualitative modeling of technical systems," Artif. Intell., vol. 170, no. 8, pp. 667-685, 2006.

[14]Liu B, "Theory and practice of uncertain programming," Phys. Heidelberg., 2002.

[15]P. Mula, S. K. Roy, and D. Li, "Birough programming approach for solving bi-matrix games with birough payoff elements,” J. Intell. Fuzzy Syst., vol. 29, pp. 863-875, 2015.

[16]C. B. Das and S. K. Roy, "Fuzzy based GA for entropy bimatrix goal game," Int. J. Uncertainty, Fuzziness Knowledge-Based Syst., vol. 18, no. 6, pp. 779-799, 2010.

[17]C. B. Das and S. K. Roy, "Fuzzy based GA to multi-objective entropy bimatrix game," Int. J. Oper. Res., vol. 50, no. 1, pp. 125-140, 2013.

[18]W. Fei and D. Li, "Bilinear programming approach to solve interval bimatrix games in tourism planning management,” Int. J. Fuzzy Syst., vol. 18, no. 3, pp. 504-510, 2016.

[19]J. GAO and X. YANG, "Credibilistic bimatrix game with asymmetric information: bayesian optimistic equilibrium strategy," Int. J. Uncertainty, Fuzziness Knowledge-Based Syst., vol. 21, no. July, pp. 89-100, 2013.

[20]L. DF and N. JX, "An interval-valued programming approach to matrix games with payoffs of triangular intuitionistic fuzzy numbers," Iran J Fuzzy Syst, vol. 11, no. 2, pp. 45-57, 2014.

[21]S. K. Roy, "Game theory underMCDMand fuzzy set theory some problems in multi-criteria decision making using game theoretic approach," Ger. VDM (Verlag Dr. Muller), 2010.

[22]J. Jana and S. K. Roy, "Solution of matrix games with generalised trapezoidal fuzzy payoffs," Fuzzy Inf. Eng., vol. 10, no. 2, pp. 213-224, 2018.

[23]A. Aggarwal, S. Chandra, and A. Mehra, "Solving matrix game with I-fuzzy payoffs: Pareto optimal security strategies approach," Fuzzy Inf Eng, vol. 6, no. 2, pp. 167-192, 2014.

[24]I. Deli and N. Cagman, "Probabilistic equilibrium solution of soft games," J Intell Fuzzy Syst, vol. 30, no. 4, pp. 2237-2244, 2016.

[25]S. KumarRoy and P. Mula, "Bi-matrix game in bifuzzy environment," J. Uncertain. Anal. Appl. https//doi.org/10.1186/2195-5468-1-11, pp. 1-11, 2013.

[26]J. Jana and S. K. Roy, "Dual hesitant fuzzy matrix games: based on new similarity measure," Soft Comput. DOI 10.1007/s00500-018-3486-1, pp. 1-10, 2018.

[27]S. K. Roy and A. Bhaumik, "Intelligent water management: A triangular type-2 intuitionistic fuzzy matrix games approach,” Water Resour. Manag., vol. 32, no. 3, pp. 949-968, 2018.

[28]M. Larbani, "Solving bimatrix games with fuzzy payoffs by introducing Nature as a third player," Fuzzy Sets Syst., vol. 160, no. 1, pp. 657-666, 2009.

[29]J. Gao, "Uncertain bimatrix game with applications," Fuzzy Optim Decis Mak., vol. 12, pp. 65-78, 2013.

[30]S. K. Roy and P. Mula, "Rough set approach to bi-matrix game," Int. J. Oper. Res., vol. 23, no. 2, 2015.

[31]S. K. Roy and P. Mula, "Solving matrix game with rough payoffs using genetic algorithm," Oper Res Int J, vol. 16, no. 1, pp. 117-130, 2016.

[32]S. Xiao and E. M. K. Lai, "Rough programming approach to power-balanced instruction scheduling for VLIW digital signal processors," IEEE Trans. Signal Process., vol. 56, no. 4, pp. 1698-1709, 2008.

[33]S. K. Roy and S. N. Mondal, "An approach to solve fuzzy interval valued matrix game," Int. J. Oper. Res., vol. 26, no. 3, pp. 253-267, 2016. 


\section{Authors' Profiles}

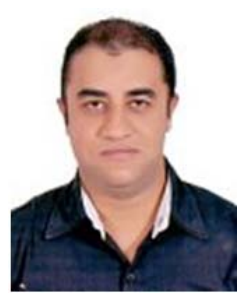

Mohamed Gaber Brikaa received his B.Sc. and M.Sc. degree in Mathematics from Faculty of Science, Suez Canal University, Egypt. Currently He is pursuing his Ph.D. degree in Mathematics at Faculty of Science, Suez Canal University, Egypt. He is currently an assistant lecturer at faculty of Computers and Informatics, Suez Canal University, Egypt. His research interest is in games theory, mathematical programming, fuzzy programming, rough programming and etc. He also is the author of many research articles published in scientific journals. More details may be found on his official website available online at https://www.researchgate.net/profile/Mohamed_Brikaa

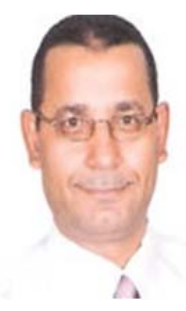

El-Saeed Ammar received his Ph.D. degree in Applied Mathematics from Technical University of Dresden, Germany in 1993. He is Professor in the Department of Mathematics, Faculty of Science, Tanta University, Tanta, Egypt. His research interests include optimization, investment, algorithms, games theory, portfolio optimization, sensitivity analysis, fuzzy set theory, global optimization, rough sets and etc. Prof. ElSaeed Ammar is the author of many research articles published in scientific journals. More details may be found on his official website available online at https://www.researchgate.net/profile/E_Ammar/info

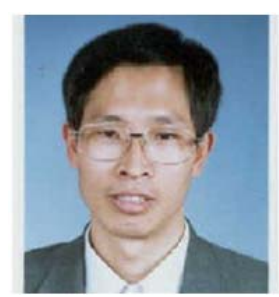

Zhoushun Zheng received his Ph.D. degree in Mathematics from Central South University, China in 2006. He is Professor in the School of Mathematics and Statistics, Central South University, China. His research interests include simulation in scientific engineering, modeling and etc. Prof. Zhoushun Zheng is the author of many research articles published in scientific journals. More details may be found on his official website available online at https://www.researchgate.net/scientificcontributions/2109246586 Zhou-Shun_Zheng

How to cite this paper: M. G. Brikaa, El-Saeed Ammar, Zhoushun Zheng," Solving Bi-matrix Games in Tourism Planning Management under Rough Interval Approach", International Journal of Mathematical Sciences and Computing(IJMSC), Vol.5, No.4, pp.44-62, 2019. DOI: 10.5815/ijmsc.2019.04.05 